ORNL/TM-2006/520

\title{
Process Modeling Phase I Summary Report for the Advanced Gas Reactor Fuel Development and Qualification Program
}

March 2006

Prepared by

S. Pannala, Research \& Development Staff Member

C. S. Daw, Distinguished Research \& Development Staff Member

D. Boyalakuntla, Post-doctoral Research Associate

C. E. A. Finney, Research \& Development Staff Member 


\section{DOCUMENT AVAILABILITY}

Reports produced after January 1, 1996, are generally available free via the U.S. Department of Energy (DOE) Information Bridge:

Web site: http://www.osti.gov/bridge

Reports produced before January 1, 1996, may be purchased by members of the public from the following source:

National Technical Information Service

5285 Port Royal Road

Springfield, VA 22161

Telephone: 703-605-6000 (1-800-553-6847)

TDD: 703-487-4639

Fax: 703-605-6900

E-mail: info@ntis.fedworld.gov

Web site: http://www.ntis.gov/support/ordernowabout.htm

Reports are available to DOE employees, DOE contractors, Energy Technology Data Exchange (ETDE) representatives, and International Nuclear Information System (INIS) representatives

from the following source:

Office of Scientific and Technical Information

P.O. Box 62

Oak Ridge, TN 37831

Telephone: 865-576-8401

Fax: 865-576-5728

E-mail: reports@adonis.osti.gov

Web site: http://www.osti.gov/contact.html

This report was prepared as an account of work sponsored by an agency of the United States Government. Neither the United States government nor any agency thereof, nor any of their employees, makes any warranty, express or implied, or assumes any legal liability or responsibility for the accuracy, completeness, or usefulness of any information, apparatus, product, or process disclosed, or represents that its use would not infringe privately owned rights. Reference herein to any specific commercial product, process, or service by trade name, trademark, manufacturer, or otherwise, does not necessarily constitute or imply its endorsement, recommendation, or favoring by the United States Government or any agency thereof. The views and opinions of authors expressed herein do not necessarily state or reflect those of the United States Government or any agency thereof. 
ORNL/TM-2006/520

\title{
PROCESS MODELING PHASE I SUMMARY REPORT FOR THE ADVANCED GAS REACTOR FUEL DEVELOPMENT AND QUALIFICATION PROGRAM
}

\author{
Shreekanth Pannala ${ }^{1}$, C. Stuart Daw ${ }^{2}$, Dhanunjay S. Boyalakuntla ${ }^{2}$, and Charles E. A. Finney ${ }^{2}$ \\ ${ }^{1}$ Computing \& Computational Sciences \\ ${ }^{2}$ Energy \& Engineering Sciences
}

March 2006

\author{
Prepared by \\ OAK RIDGE NATIONAL LABORATORY \\ P.O. Box 2008 \\ Oak Ridge, Tennessee 37831-6285 \\ managed by \\ UT-Battelle, LLC \\ for the \\ U.S. DEPARTMENT OF ENERGY \\ under contract DE-AC05-00OR22725
}





\section{CONTENTS}

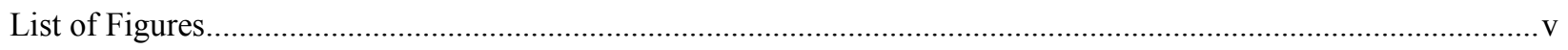

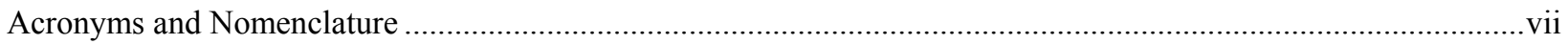

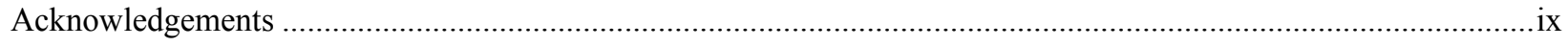

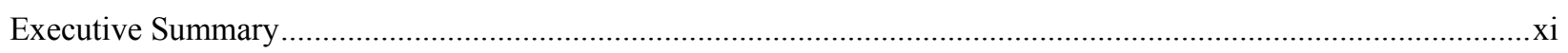

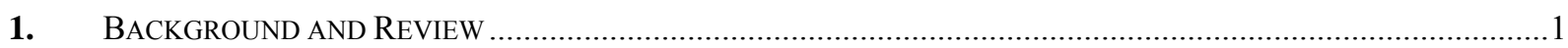

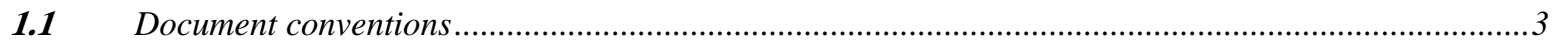

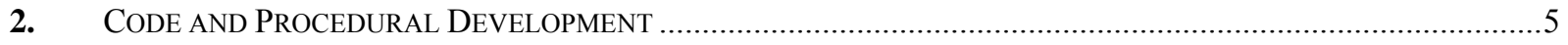

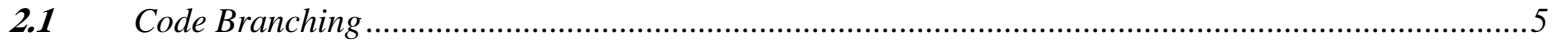

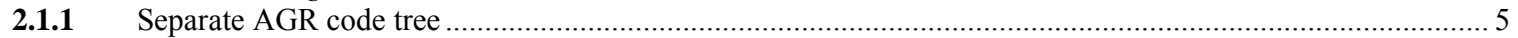

2.1.2 Identify and Fix Parameters for AGR Phase II scale-up modeling............................................................... 5

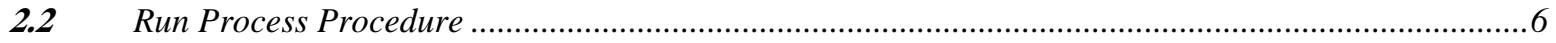

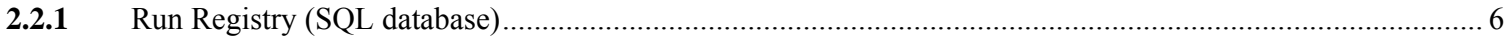

2.2.2 Run Setup and Results Review Process ......................................................................................

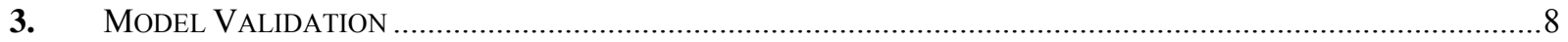

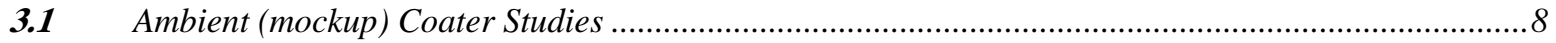

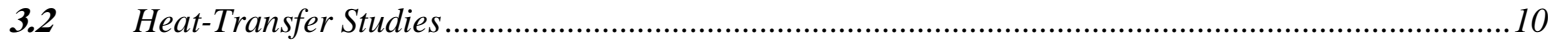

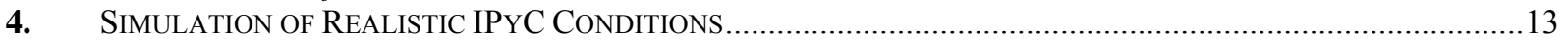

4.1 Distributor Discrimination (Multi-hole vs. Single-hole Injector) ........................................................13

$4.2 \quad$ Operating Condition Discrimination (Temperature Variation).............................................................21

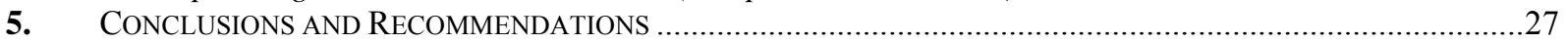

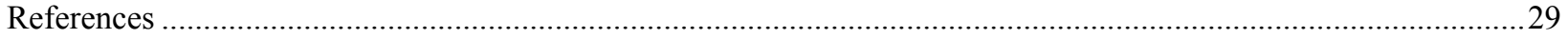

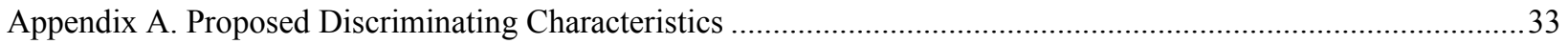





\section{LIST OF FIGURES}

Fig. 1. Centerline time-average axial gas velocity versus axial location for the UTK mockup spouted bed. The solid blue line is from simulation and the red line with points from experiment. The specific operating condition is for a bed inventory of $54.5 \mathrm{~g}$ of $500 \mu \mathrm{m} \mathrm{ZrO2}$ and an inlet air flow of $3000 \mathrm{~cm} / \mathrm{s}$.

Fig. 2. Inlet-pressure cycle frequency versus wall temperature from simulation and experimental measurements of the ORNL 2-inch surrogate coater. The operating condition is for $54.5 \mathrm{~g}$ of $500 \mu \mathrm{m} \mathrm{ZrO2}$ with 8 SLPM of inlet nitrogen.

Fig. 3. Snapshots from two pulsation cycles of the side view of the spouted bed with multi-hole injector. Plotted are the translucent solid contours of the void fraction (similar to peering into a glass bed filled with transparent marbles colored with local void fraction) along with void fraction contour surface corresponding to void fraction of 0.99 . The void fraction surface represents a visual border between particles and gas. Here, the dynamic behavior of the spout along with the side-to-side sloshing of the bed is very evident. The color scheme for the void fraction is blue for solids and red for gas. The movie may be found at http://www.mfix.org/ORNL-TM-2006-520/Fig03.mpg .

Fig. 4. Snapshots from two pulsation cycles of the side view of the spouted bed with the single-hole injector. Plotted are the translucent solid contours of the void fraction (similar to peering into a glass bed filled with transparent marbles colored with local void fraction) along with void fraction contour surface corresponding to void fraction of 0.99 . The void fraction surface represents a visual border between particles and gas. Here, unlike in Fig. 3, the spout is very stable to lateral motion with the fountain motion limited to the axial motion. The color scheme for the void fraction is blue for solids and red for gas. The movie may be found at http://www.mfix.org//ORNL-TM-2006-520/Fig04.mpg .

Fig. 5. Snapshots of the close-up of the multi-hole injector. Plotted are the centerline slice translucent solid contours of the $\mathrm{H}_{2}$ mass fraction along with temperature contour surface corresponding to temperature of $800 \mathrm{~K}$. The temperature surface represents a visual border between cold gas from the injectors to the hot gas in the coater. Here, the dynamic behavior of the inlet jets along with the hole-to-hole variation is evident. The color scheme for the $\mathrm{H}_{2}$ mass fraction is blue for zero concentration and red for highest concentration. The movie may be found at http://www.mfix.org/ORNL-TM-2006-520/Fig05.mpg ........16

Fig. 6. Snapshots of the close-up of the single-hole injector. Plotted are the centerline slice translucent solid contours of the predicted $\mathrm{H}_{2}$ mass fraction along with temperature contour surface corresponding to temperature of $800 \mathrm{~K}$. The temperature surface represents a visual border between cold gas from the injectors to the hot gas in the coater. The color scheme for the $\mathrm{H}_{2}$ mass fraction is blue for zero concentration and red for highest concentration. The movie may be found at http://www.mfix.org/ORNLTM-2006-520/Fig06.mpg .

Fig. 7. Snapshots of the top view of the void fraction surface contour of 0.99 for multi-hole injector showing sloshing of the spout. This void fraction surface represents a visual border between particles and gas and is equivalent to a visual observation in the experiment from the top. The movie may be found at http://www.mfix.org/ORNL-TM-2006-520/Fig07.mpg .

Fig. 8. Top view of multi-hole injector coater experiments. The conditions in this experiment are different from the simulations in Fig. 7 but this figure is shown here to illustrate the sloshing of the spout as observed in the simulations. The movie may be found at http://www.mfix.org/ORNL-TM-2006-520/Fig08.mpg . ....18

Fig. 9. Comparison of the pressure PSDs for the single- and multi-hole cases, from MFIX output. The PSDs clearly show the reduced frequency in the multi-hole case along with formation of complex sub-harmonics related to the sloshing motion of the bed.

Fig. 10. Void fraction (first column, EP_g), temperature (second column, $\mathrm{T} \_\mathrm{g}$ ) and $\mathrm{H}_{2}$ species mass fraction (third column, $\mathrm{X} \_\mathrm{g}$ ) at six different time steps during the spouting process for baseline case 1 . Here, the relationship between the hydrodynamics pinching, temperature pulse and the species concentration is evident. The color scheme for the void fraction is blue for solids and red for gas; for temperature and species mass fraction, red for high and blue for low values (see numerical values at top). The movie may be found at http://www.mfix.org/ORNL-TM-2006-520/Fig10.mpg . 
Fig. 11. Instantaneous temperature solid contours at four different instants during the spouting process for baseline case $1(1548 \mathrm{~K}$ ). In addition, two contour lines corresponding to $800 \mathrm{~K}$ (white) and $1400 \mathrm{~K}$ (black) are plotted to cold and high temperature gases. The movie may be found at http://www.mfix.org/ORNL-TM2006-520/Fig11.mpg.

Fig. 12. Instantaneous temperature solid contours at four different instants during the spouting process for case 2 (1443K). Contour lines corresponding to $800 \mathrm{~K}$ (white) and 1400K (black) are plotted to cold and high temperature gases. The movie may be found at http://www.mfix.org/ORNL-TM-2006-520/Fig12.mpg . 24

Fig. 13. Instantaneous temperature solid contours at four different instants during the spouting process for baseline case $3(1598 \mathrm{~K}$ ). Contour lines corresponding to $800 \mathrm{~K}$ (white) and $1400 \mathrm{~K}$ (black) are plotted to cold and high temperature gases. The movie may be found at http://www.mfix.org/ORNL-TM-2006- 


\section{ACRONYMS AND NOMENCLATURE}

$\begin{array}{ll}\text { AGR } & \text { Advanced Gas Reactor } \\ \text { BPP } & \text { Ballistic Particle Profile, a proposed discriminating characteristic } \\ \text { CARPT } & \text { Computed Automated Radioactive Particle Tracking } \\ \text { CH } & \text { Centerline static core height } \\ \text { CVS } & \text { Concurrent Version System } \\ \text { DC } & \text { Discriminating Characteristic } \\ \text { DSCT } & \text { Dimensionless Solids Cycle Time, a proposed discriminating characteristic } \\ \text { FBCVD } & \text { Fluidized Bed Chemical Vapor Deposition } \\ \text { FY } & \text { Fiscal Year } \\ \text { INL } & \text { Idaho National Laboratory } \\ \text { IPyC } & \text { Inner Pyrolytic Carbon (also known as pyrocarbon) } \\ \text { ISU } & \text { Iowa State University } \\ \text { MFIX } & \text { Multiphase Flow with Interphase eXchanges } \\ \text { NSIR } & \text { Net Solids-wall Impact Rate, a proposed discriminating characteristic } \\ \text { NUCO } & \text { Natural (0.71\% } 23 \text { U) uranium mixture of UO }{ }_{2} \text { and UC } \text { C }_{2} \\ \text { OPyC } & \text { Outer Pyrolytic Carbon (also known as pyrocarbon) } \\ \text { ORNL } & \text { Oak Ridge National Laboratory } \\ \text { PSD } & \text { Power Spectral Density } \\ \text { SiC } & \text { Silicon Carbide } \\ \text { SLPM } & \text { Standard Liters Per Minute } \\ \text { SQL } & \text { Structured Query Language } \\ \text { TRISO } & \text { Tri-structural isotropic } \\ \text { Umf } & \text { Minimum fluidization velocity } \\ \text { UTK } & \text { University of Tennessee, Knoxville }\end{array}$




\section{ACKNOWLEDGEMENTS}

The authors acknowledge the contributions of many individuals to the content of this report. Rick Lowden and Jim Miller, who are part of the ORNL coating team, have helped greatly in conducting the surrogate coater experiments and providing additional insight into the process from the experimental viewpoint. Thomas O'Brien and Madhava Syamlal (National Energy Technology Laboratory) have given invaluable input on various modeling issues. Duane Bruns and his team at the University of Tennessee have been helpful with the data acquisition on the spouted-bed section and related experiments. Thanks are also due to Madeline Feltus (DOE HQ Program Manager) and Gary Bell (ORNL Project Execution Manager) for program direction and support. 


\section{EXECUTIVE SUMMARY}

This report summarizes the results of preliminary work at Oak Ridge National Laboratory (ORNL) to demonstrate application of computational fluid dynamics modeling to the scale-up of a Fluidized Bed Chemical Vapor Deposition (FBCVD) process for nuclear fuels coating. Specifically, this work, referred to as Modeling Scale-Up Phase I, was conducted between January 1, 2006 and March 31, 2006 in support of the Advanced Gas Reactor (AGR) Program. The objective was to develop, demonstrate and "freeze" a version of ORNL's computational model of the tri-structural isotropic (TRISO) fuel-particle coating process that can be specifically used to assist coater scale-up activities as part of the production of AGR-2 fuel. The results in this report are intended to serve as input for making decisions about initiating additional FBCVD modeling work (referred to as Modeling Scale-Up Phase II) in support of AGR-2.

The main computational tool used to implement the model is the general-purpose multiphase fluiddynamics computer code known as MFIX (Multiphase Flow with Interphase eXchanges), which is documented in detail on the DOE-sponsored website http://www.mfix.org. Additional computational tools are also being developed by ORNL for post-processing MFIX output to efficiently summarize the important information generated by the coater simulations. The summarized information includes quantitative spatial and temporal measures (referred to as discriminating characteristics, or DCs) by which different coater designs and operating conditions can be compared and correlated with trends in product quality.

The ORNL FBCVD modeling work is being conducted in conjunction with experimental coater studies at ORNL with natural uranium CO (NUCO) and surrogate fuel kernels. Data are also being obtained from ambient-temperature, spouted-bed characterization experiments at the University of Tennessee and theoretical studies of carbon and silicon carbide chemical vapor deposition kinetics at Iowa State University. Prior to the current scale-up activity, considerable effort has gone in to adapting the MFIX code to incorporate the unique features of fuel coating reactors and also in validating the resulting simulation features with experimental observations. Much of this work is documented in previous AGR reports and publications (Pannala et al., 2004, Pannala et al., 2005, Boyalakuntla et al., 2005a, Boyalakuntla et al., 2005b and Finney et al., 2005).

As a result of the previous work described above, the ORNL coater model now has the capability for simulating full spatio-temporal details of the gas-particle hydrodynamics and gas-particle heat and mass transfer in the TRISO coater. This capability provides a great deal of information about many of the processes believed to control quality, but the model is not yet sufficiently developed to fully predict coating quality for any given coater design and/or set of operating conditions because the detailed chemical reaction kinetics needed to make the model fully predictive are not yet available. Nevertheless, the model at its current stage of development already provides the most comprehensive and detailed quantitative information available about gas flows, solid flows, temperatures, and species inside the coater during operation. This level of information ought to be highly useful in expediting the scale-up process (e.g., in correlating observations and minimizing the number of pilot-scale tests required). However, previous work had not yet demonstrated that the typical design and/or operating changes known to affect product quality at the lab scale could be clearly discriminated by the existing model. The Modeling Scale-Up Phase I work was initiated to produce such a demonstration, and two detailed examples are discussed in this report.

Also, it was recognized that any model used to support near-term AGR-2 design studies will have to be kept "frozen" or "standardized" (i.e., the code remains unchanged), even though future improvements might be made to the original ORNL FBCVD model as part of other AGR activities. The development of this standardized version of the model and a process for ensuring consistent computational quality control safeguards were completed under Phase I, and these are described in detail in the report. 
The key overall conclusions of the ORNL modeling team based on the Phase I results are:

- The standard version of the ORNL FBCVD model is quite responsive to design and/or operating changes associated with the coater inlet gas distribution. As changes to inlet gas distribution is one of the key issues for scale-up, the model should be very useful for discriminating among proposed scale-up options.

- Coating quality is known to be a strong function of local temperatures and reactant gas temperature gradients near the coater inlet, and these effects are clearly captured by the standard model.

- The list of discriminating characteristics originally proposed for the scale-up studies associated with AGR-2 should be expanded to include more detailed measures of spatial and temporal variations in temperature and reactive species. A modified DC list that can be fully generated using the standard model has been proposed.

- The model validation studies have produced a modified version of MFIX which seems to compare well both with experimental measurements both from ambient mockup coater as well as surrogate coater operated at realistic coating conditions.

- Besides staff time, the most critical limiting resource in utilizing the ORNL FBCVD model for assisting with AGR-2 scale-up is parallel computing availability. These two factors will determine how many different design/operating options could be considered in the coming months. 


\section{BACKGROUND AND REVIEW}

This report provides a brief overview of the AGR TRISO fuels-coating computational-modeling effort and summarizes in more detail the results of Phase I activities toward applying the model to coater scaleup. The overall goal of the modeling effort is to develop a robust, physically based, experimentally validated computational model of the fuel particle coating process that can assist the transition from laboratory to production scale. The availability of such a model is expected to be an important asset in developing and demonstrating a fabrication process that can produce coated fuels with performance matching or exceeding that of the German fuel of the late 1980s (Heit, 1986). Specifically, the ability to simulate internal details of the fluidized bed chemical vapor deposition (FBCVD) process should significantly reduce the time required for empirical development and optimization (for example, the development of the production-scale German fuel coater took 20 years of empirical effort). Although empiricism is reduced, careful experimental validation is still a crucial component of computational modeling to ensure that model predictions accurately reflect real physics and chemistry. Because of the coating process complexity, model development is planned as a sequence of steps that make maximal use of available information at each point. In addition, it is expected that a sequential approach will make it possible to start producing useful information long before the all the details of the FBCVD process have been fully captured. The resulting modeling plan addresses the dominant coater physics and chemistry in the following order:

1) Hydrodynamics

2) Heat and Mass Transfer

3) Chemical Kinetics of Reaction/Deposition

4) Particle Evolution

Hydrodynamics is a logical beginning point for modeling because it defines the global environment in which the fuel particles and reactant gases are mixed and heated. Also, this part of the physics involves highly complex spatial and temporal changes that are virtually inaccessible experimentally but that can be readily tracked with high performance computers. The main elements of the FBCVD coater hydrodynamics were previously implemented in the MFIX code and are described in detail in Pannala et al., 2004. One of the most important hydrodynamic features observed in experiments and replicated by the model was the global solids circulation cell produced by the action of the upward flowing reactant gas as it is injected into the bed of fuel particles. The spatial and temporal details of this global solids circulation cell directly influence coating quality because they determine the length of time each particle is repeatedly exposed to the sequence of reaction/deposition/annealing steps that constitute the coating process. To help quantify the details of the circulation cell, a particle tracer algorithm was developed for post-processing the MFIX simulation outputs. With this tool, it is possible to quantitatively estimate the particle trajectories (in terms of stationary statistical distributions) for any specified coater geometry and operating condition.

Heat transfer in the FBCVD process was implemented in the MFIX code in FY2005 as described in Boyalakuntla et al., 2005 and Finney et al., 2005. The current default Nusselt number (Nu) correlation for gas-particle heat transfer in MFIX is that by Gunn, 1978. The Gunn correlation was selected for the interim until more accurate experimental correlations developed specifically for fuels coating become available. The Gunn correlation was derived from a broad body of multiphase flow measurements and has been found by the MFIX development team at the National Energy Technology Laboratory (Morgantown, West Virginia) to be widely applicable in many types of fluidization reactors. If improved $\mathrm{Nu}$ correlations become available in the future for fuel coaters, they can easily be implemented in the ORNL coater model to replace the Gunn correlation. With the Gunn correlation in MFIX activated, 
extensive studies of the resulting predictions were made in 2005. Example results of the latter are included in this report. The simulations clearly reveal that the high rate of gas heating and expansion in the lower section of the coaters produces some unique spout effects not seen in more conventional spouted bed reactors. The rapid gas expansion also has a significant impact on the global solids circulation, which cannot be replicated by ambient-temperature experiments. One direct experimental observable associated with the altered circulation and successfully predicted by MFIX is the downward shift in pulsation frequency of the inlet gas flow.

The default MFIX mass-transfer correlation currently used for the gas-particle Sherwood number is that developed by Gunn, 1978. The uncertainty in available gas-particle mass-transfer correlations in the literature is greater than for heat-transfer correlations, mainly because of the greater difficulty in obtaining accurate experimental measurements of the latter. Mass transfer is also more complicated for the FBCVD process because of the complex combination of homogeneous and heterogeneous reactions occurring in series with the mass transfer, thus making it very difficult to separate the effects of mass transport from intrinsic chemical kinetics. While it is expected that the current default mass-transfer correlation in MFIX will be adequate for discriminating trends, more accurate mass-transfer estimates will require experimental measurements in highly controlled experiments with spouted beds that have designs and operating conditions relevant to fuel particle coating. As with the gas-particle Nusselt number correlation, improved Sherwood number correlations can be readily inserted in the ORNL FBCVD model as soon as they become available.

During the October 2005 scale-up meeting at ORNL, the INL and ORNL scale-up teams agreed that the existing ORNL coater model ought to be able to provide useful information for recommending distributor designs and operating conditions to be tested in future pilot-scale experiments, even though fully predictive chemistry and chemical kinetics are not yet available. As a result of this consensus, it was agreed that ORNL should continue exploring the capabilities of the model with the objective of demonstrating its readiness as a tool in support of AGR-2 scale-up. It was also agreed that this demonstration process would be implemented in two phases: the first phase focusing on discriminating example "good" and "bad" cases of surrogate coating runs with the ORNL 2-inch coater, and the second phase focusing on discriminating a small set of proposed distributor designs and operating conditions for the BWXT 6-inch pilot tests. The initiation of the second phase would start only after completion and assessment of results from the first phase. The agreed-upon details for these Phase I and Phase II stages were:

Phase I (Duration 3 months starting January 1, 2006):

- Define a "standard" version of the ORNL coater model and an associated set of quantitative measures that can be used to compare candidate coater configurations defined by the scale-up team. This standard version is to be kept separate from future improved versions of the model so that any comparisons made during the remainder of FY2006 will be consistent. (Further improvements can be made to the ORNL code in support of more general AGR goals, but these versions would be kept distinct).

- Use the standard model to simulate a "good" versus "bad" quality case among the 2-inch ORNL laboratory pyrolytic carbon (IPyC) runs and demonstrate that the quality differences correlate with relevant physical quantities predicted by the model.

- Run limited 3D standard-model simulations of the 2-inch coater under realistic IPyC coating conditions with single versus multi-hole inlet gas injectors to demonstrate that the model at least qualitatively captures the experimentally observed global mixing differences for these two cases.

- Modify the current ORNL FBCVD internal planning package form to reflect the above work and Phase II planning. 
Phase II (Duration 6 months starting April 1, 2006):

- Review results from Phase I to determine if Phase II should proceed.

- Initiate non-disclosure agreements (NDAs) with Iowa State University (ISU) and the University of Tennessee (UTK). Once these are in place, the INL scale-up team will share the top contending coating-bed configurations with ORNL and the university partners.

- Establish a weekly teleconference among the modeling and scale-up teams to promote better communication. In addition, a mailing list and/or web portal will be established to make it easier to exchange/archive data files and related documents.

- Simulate $X$ configurations in 2D and Y configurations in 3D at ORNL and ISU. X and Y need to be estimated based on the complexity of the configurations. X, Y will be determined based on the available funding.

- Develop plans for further scale-up studies and coater optimization for FY2007 and FY2008.

In the Phase I tasks defined in October 2005, three distinct coating stages were identified for detailed simulation - buffer, IPyC and $\mathrm{SiC}$ - but this report focuses only on the IPyC coating stage. This more limited focus was taken in the interest of time (to explore the multi-hole cone in greater detail) and because the bulk of available experimental data available for comparison with simulations is from this coating stage.

In the following sections we discuss the procedures established to standardize the ORNL coater model and various recommended parameter values to be used for Phase II. Following that, we summarize an internal code review/registry process developed to ensure the quality of any comparisons made in Phase II. We also provide a brief summary of the model validations made against experimental data from ambient and elevated temperature experiments, and we describe limited simulations with different injectors and operating conditions that illustrate the level of discrimination provided by the standard ORNL coater model. We end with a list of specific conclusions and recommendations relevant to the proposed Phase II.

\subsection{DOCUMENT CONVENTIONS}

In this document, the physical units employed are CGS (cm-g-s), which is used by the MFIX program. As exceptions, coater sizes are labeled in inches, following the nomenclature convention of the AGR program, and particle sizes are reported in microns.

Following the convention of the spouted-bed research community, the spouted-bed system is divided into three regions: the fountain, the annular zone, and the spout or core. "Core" and "spout" are used interchangeably in this document. 


\section{CODE AND PROCEDURAL DEVELOPMENT}

\subsection{CODE BRANCHING}

The MFIX codebase is stored in a Concurrent Version System (CVS) repository, which allows for strict documentation of any changes to the code. Additionally, it allows for extraction of a code snapshot at any instant in time, meaning that earlier versions from the current CVS codebase can be used if desired. During coater model development, changes to the code and associated operating parameters are inevitable as model optimization proceeds. The base MFIX code itself is mature, so significant changes to it are relatively infrequent. Most changes occurring in the ORNL coater model are associated with selecting different MFIX computational options, adding special user submodels, or adjusting input parameter values. For purposes of comparing potential distributor designs and/or operating conditions in Phase II of the AGR scale-up assistance, it has been decided that a fixed or "standard" version of the ORNL coater model is needed to make sure comparisons are consistent. The standard coater model to be used is constructed from a specific implementation of MFIX with specific selected options and associated run parameters that do not depend on the design or operating variations being considered.

\subsubsection{Separate AGR code tree}

Near the end of Phase I, a special version of the ORNL AGR coater code was set aside and designated as version AGRII-0. This code tree is maintained separately from the more general ORNL AGR research coater code development tree and is intended not to change over the course of Phase II. The AGRII-0 version of the code will be used for all Phase II simulation runs unless the INL and ORNL scale-up teams mutually agree at some critical point that further changes are justified. In the event of the latter, a new standard version number will be defined, and if necessary, any prior simulation results that might be relevant would be re-run. Such an eventuality is considered highly unlikely and should be avoided if at all possible.

\subsubsection{Identify and Fix Parameters for AGR Phase II scale-up modeling}

The operating parameters used in AGR simulations fall under two general types: submodels or formulations, and physical parameters. Submodels might refer to gas-solids drag models or to solidsstress models, and physical parameters might refer to particle or gas properties. During the modelvalidation process for hydrodynamics and heat transfer as part of the scheduled AGR model development and validation, certain operating parameters have been found to produce the highest-fidelity simulations. Most physical properties are openly available in databases or references, but some values, such as particle angle of internal friction or coefficient of restitution, have had to be measured specifically for the AGR modeling work. At the end of Phase I, the complete set of input parameters in AGRII-0 have been fixed. Only design or operating parameters (such as gas flow rates or boundary conditions) are expected to be adjusted in Phase II. 
Table 1. Primary parameters related to the fixed version of MFIX

\begin{tabular}{|c|c|c|}
\hline Property & Value & Comments \\
\hline \multicolumn{3}{|c|}{ Submodels } \\
\hline Stress model & Schaeffer & \\
\hline Stress blending & Modified sigmoidal & \\
\hline \multirow[t]{2}{*}{ Drag model } & Syamlal-O’Brien & Homogeneous temperature \\
\hline & Gidaspow (blended) & Heterogeneous temperature \\
\hline Granular temperature & PDE & \\
\hline \multicolumn{3}{|c|}{ Gridding } \\
\hline Maximal grid size in particle zone & $10 \times \mathrm{d}_{\mathrm{p}}$ & \\
\hline Minimal gas jet inlet resolution & 4 cells & \\
\hline \multicolumn{3}{|c|}{ Physical parameters } \\
\hline Angle of internal friction, $\varphi$ & $15^{\circ}$ & Varies with particles \\
\hline Void fraction at $\mathrm{U}_{\mathrm{mf}}$ & 0.42 & Varies with particles \\
\hline
\end{tabular}

Table 1 lists the selected operating submodels and parameters for AGRII-0. Some parameters, such as angle of internal friction, coefficient of restitution or void fraction at minimum fluidization, actually vary as a function of particle properties, temperature or velocity. For the purpose of this document, median values are used.

\subsection{RUN PROCESS PROCEDURE}

Over the past two years, the modeling team has adapted the MFIX code and the associated particle property parameters to match reasonably well the observed coater behavior over a range of operating conditions (e.g., gas flows and compositions, particles, temperatures). This particular submodel and parameter set has been found to produce the highest-fidelity simulations compared with available experimental data. As part of the code branching, the preferred parameter set as well as strict code versioning have been identified and will be employed in any of the AGR-2 Phase II scale-up modeling. Whereas this freezing of code and parameters reduces the number of input changes for any simulation, there will still be changes required for each different case (e.g., initial or boundary conditions). Thus there is always a need to guard against unintentional corruption of unchanging standard inputs.

\subsubsection{Run Registry (SQL database)}

To address the need for individual run review and quality control, a pre-execution review procedure has been established. This procedure specifies steps to be taken during the simulation setup, execution, and data post-processing. Tracking is achieved through a run registry, which lists relevant setup details in a database managed via a MySQL server, which accesses the database via commands in Structured Query Language (SQL). This registry facilitates easy searches of all simulation runs for later data mining, besides fulfilling its purpose of documenting desired run parameters for the reviewer. Additionally, the registry allows the assignment of a unique case number for labeling purposes.

\subsubsection{Run Setup and Results Review Process}

Each simulation author is responsible for preparing the coater model input file, for securing and compiling the code into an executable, and for entering the relevant parameters into the run registry. To assist pre-execution reviews, a special header is placed in the setup file so that the purpose of the run is 
self-documenting. Each reviewer, selected from the ORNL modeling team, verifies that the setup header and registry entries match the parameters specified in the setup file, and that the proper version of the code is being used. Simulations are not started until the review is complete. While running, the data can be examined periodically to check progress and integrity. After execution is complete, the simulation author runs a series of post-processing tests to verify that the output data falls within norms of stability, stationarity and integrity. Once this post-run review is complete, the data are analyzed using whichever methods (e.g., discriminating characteristics) have been specified for normal data examination. 


\section{MODEL VALIDATION}

The adapted MFIX code used in modeling the AGR spouted-bed coater has undergone extensive development over the past two years. A key aspect of the development process has been utilization of experimental data to validate that model predictions are physically reasonable. Following the AGR programmatic schedule, validation has occurred in distinct stages. The first stage was validation of the hydrodynamics of the spouted bed at ambient conditions, based on experiments at the University of Tennessee and Oak Ridge National Laboratory; this work was reported in 2004 (Pannala et al., 2004). The second stage was validation of heat and mass-transfer models, based on experiments at ORNL; this work was reported in 2004 for surrogate materials (Boyalakuntla et al., 2005) and for NUCO particles (Finney et al., 2005).

Direct measurements of the detailed processes occurring inside the FBCVD coater are extremely difficult because of the high temperature, reactive atmosphere, highly transient flow, dense particle concentration, and spatially confined access. Available sensors (e.g., thermocouples, gas velocity probes, extractive gas analyzers) are typically limited by slow response, spatial averaging, or other types of biasing that greatly reduce the reliability of the information obtained. In particular, it is currently impossible to directly obtain reliable quantitative measurements of the precise local conditions under which the particle coatings are actually formed. Instead, it is necessary to apply physical reasoning along with appropriate engineering assumptions and/or correlations to make inferences about the local conditions from the limited measurements available. Meaningful comparisons of the detailed output from the ORNL coater model with experiments require appropriate allowances for the inherent biasing and crudeness of the experimental measurements.

Keeping the above sensor limitations in mind, we summarize below some of the most reliable comparisons possible between the simulation predictions and measurements from both ambient and hightemperature experiments. In most cases we are able to show consistent trends, even when it is not possible to match absolute values. In future studies it may be possible to improve our ability to make such comparisons by developing models of the experimental measurement apparatus (i.e., creating virtual sensors) so that the biasing effects can be properly accounted for. Also, in limited instances, it may be possible to utilize highly specialized measurement systems such as Computer Automated Radioactive Particle Tracking (CARPT) which can overcome some of the barriers limiting conventional sensors. The use of CARPT for more direct model validation is, in fact, one of the key components proposed for the Phase II activity.

\subsection{AMBIENT (MOCKUP) COATER STUDIES}

Considerable prior research with spouted bed reactors has shown that the global hydrodynamics (and gassolids mixing) are highly correlated with several experimentally accessible measurements including:

- Time-average gas-velocity profiles

- Time-average fountain dimensions

- Dynamic inlet-gas pressure fluctuations

Time-average gas velocities were measured with a Prandtl static probe for ambient-temperature spouted beds at the University of Tennessee that were configured to simulate the 2-inch surrogate coaters at ORNL (Zhou et al., 2005). The probe was oriented vertically and extended into the fountain from above so that both radial and axial gas velocity profiles were measured. Time-average fountain dimensions for the UTK beds were also measured using video image analysis. While there is no direct relationship 
between visual estimates of fountain dimensions and the actual particle loadings predicted by MFIX, it is possible to make general comparisons of the overall time-average fountain features. High-speed measurements of experimental inlet-gas pressure fluctuations, on the other hand, directly reflect the complex gas-particle interactions near the bed inlet and provide one of the few truly dynamic measurements that can be compared with minimal translation to model predictions. The latter measurements are routinely available from the UTK experiments. Considering the ready availability of the above measurements at ambient temperature, it was decided they would be useful for validation of the basic model hydrodynamics, even though they do not include the important thermal effects described previously.

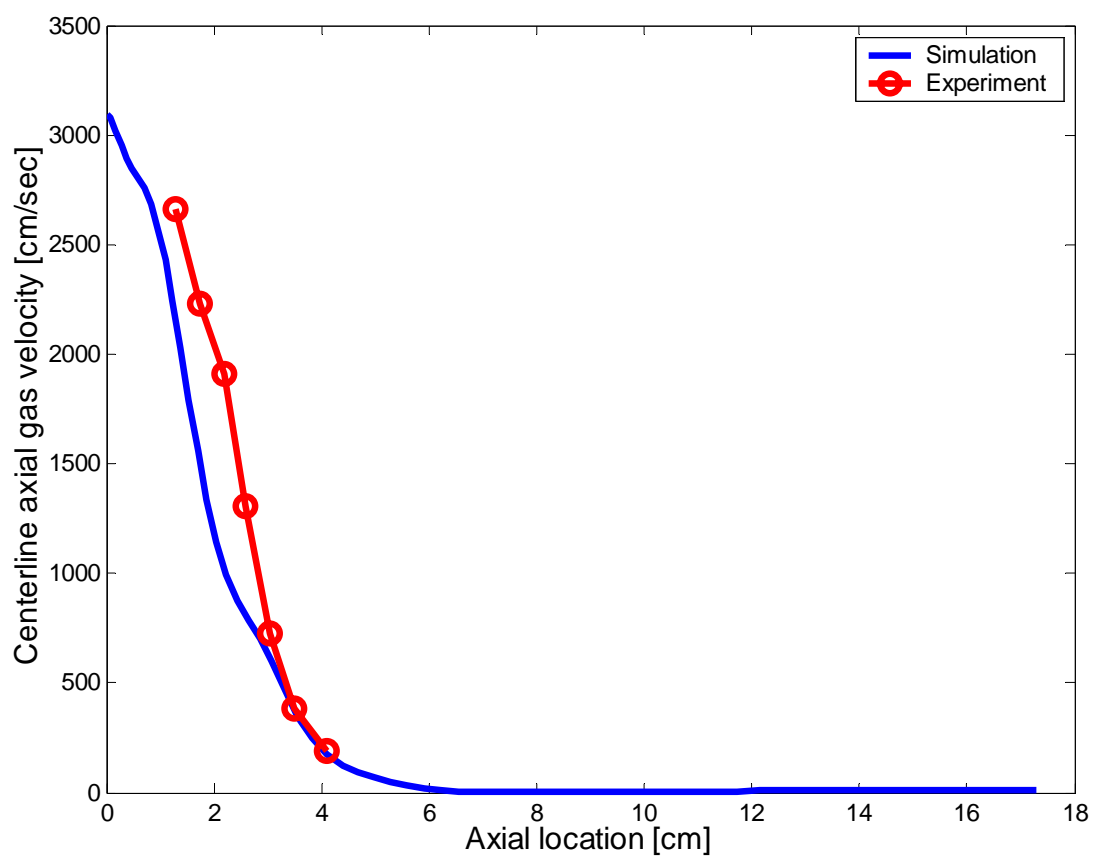

Fig. 1. Centerline time-average axial gas velocity versus axial location for the UTK mockup spouted bed. The solid blue line is from simulation and the red line with points from experiment. The specific operating condition is for a bed inventory of $54.5 \mathrm{~g}$ of $500 \mu \mathrm{m} \mathrm{ZrO2}$ and an inlet air flow of $3000 \mathrm{~cm} / \mathrm{s}$.

Figure 1 shows an example comparison between the predicted and measured centerline time-average axial gas velocities in the UTK mockup bed. The measured and simulated velocities converge at the inlet (axial location $0-1 \mathrm{~cm}$ ) and the cone top $(4 \mathrm{~cm})$, but there is some divergence in the spout zone. The simulated spout width may be wider than the experimental system, which would result in lower predicted velocities than those measured. Also, the measured velocities are biased by the presence of the probe, which creates an upward "bypass" channel for the gas and makes experimental measurement at axial location 0 undesirable.

Additional details about the hydrodynamics validation studies are provided in Pannala et al., 2004. 


\subsection{HEAT-TRANSFER STUDIES}

Internal coater temperature measurements under more realistic (high-temperature) operation are extremely difficult for the reasons noted above. However, as with the ambient-temperature experiments, measurement of inlet-gas pressure fluctuations for heated spouted beds is relatively simple. Such pressure measurements can be useful for indirectly validating heat transfer estimates because of the strong coupling between the gas temperature and hydrodynamics. We utilized this relationship for validating the model by comparing the predicted inlet gas fluctuation frequency with the corresponding frequency observed during operation of the ORNL 2-inch surrogate coater over a wide range in temperature. As shown in Fig. 2, the decreasing trend of pulsation frequency with temperature is consistent for both the model and experiments. While the absolute pulsation magnitudes diverge at the lowest temperature, we know that some degree of offset can be produced by details in the frequency response of the plumbing of the pressure probe system. For example, the duplicate ambient temperature runs at UTK and ORNL exhibited a $2 \mathrm{~Hz}$ offset over a range of gas flows. Also, the low-temperature error of the model, as seen in the figure, in this case is known to be increased by use of a gas-particle drag model that is more accurate for typical coater operating temperatures.

A more direct approach for evaluating model predictions is to compare time average temperature measurements with model predictions. The complication in doing this is that under typical coater operation, any thermocouple inserted into the coater reaches an actual temperature that is distinct from the temperatures of both gas and particles at any location. This measured temperature bias occurs because of combined, simultaneous heat transfer with both gas and solids (and with the coater walls above the particle bed). Thus observed thermocouple readings are always some complex function of the gasthermocouple, wall-thermocouple and particle-thermocouple heat transfer.

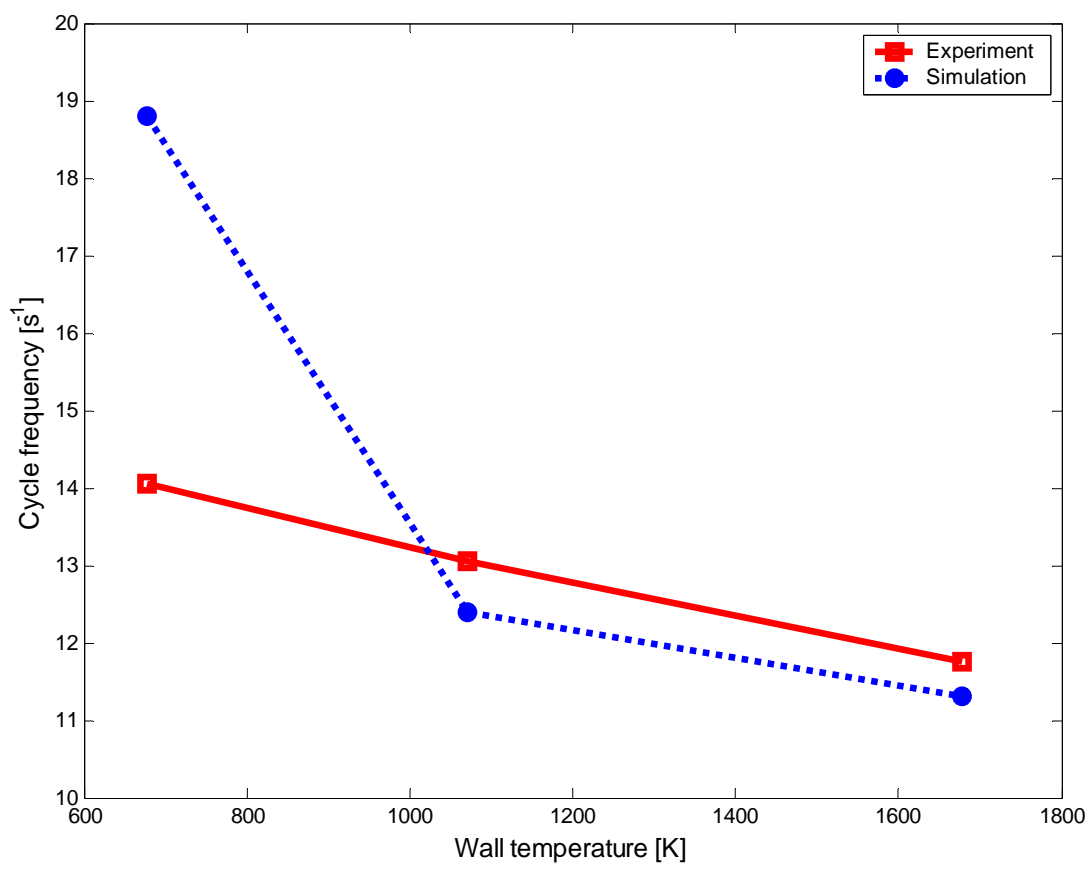

Fig. 2. Inlet-pressure cycle frequency versus wall temperature from simulation and experimental measurements of the ORNL 2-inch surrogate coater. The operating condition is for $54.5 \mathrm{~g}$ of $500 \mu \mathrm{m}$ ZrO2 with 8 SLPM of inlet nitrogen. 
However, even given this complexity in interpreting thermocouple readings, it is possible to determine if the model simulations of inlet gas heating are at least of the right order. Thermocouple measurements of the ORNL 2-inch surrogate coater provide support that the model predictions are indeed reasonable (Miller, 2004). In these experiments, the ORNL coater was operated with a charge of $97.5 \mathrm{~g}$ of $\mathrm{HfO}_{2}$ and $15 \mathrm{SLPM} \mathrm{H}_{2}$ gas fluidized at 1774K. A 1.6-mm-diameter type C Mo-sheathed thermocouple was inserted into the spouted bed through the single central gas inlet upwards from the bottom of the coater. From these observations it is clear that the thermocouple had converged to the final bed temperature by the time it reached the top of the bottom cone. A simple analysis of thermocouple heat transfer reveals that the gas must also have been fully heated by the time it reached this location, because it would otherwise have cooled the thermocouple to read below bed temperature.

For the above example case, the model predicts that the gas heating should be essentially completed over this same general region of the spout. Perhaps even more significantly, a simplified analysis of thermocouple bias near the inlet shows that the effect of the bias on estimating the gas heating rate near the coater inlet should be relatively small. From the simulation, we see that the predicted temperature gradient for the gas at the inlet is slightly below $500 \mathrm{~K} / \mathrm{cm}$. Based on a polynomial fit of the experimental thermocouple measurements, we estimate that the observed thermal gradient at the gas inlet was about $420 \mathrm{~K} / \mathrm{cm}$, which is remarkably close to the prediction.

More details of the previous heat-transfer validation studies can be found in Boyalakuntla et al., 2005 and Finney et al., 2005. 


\section{SIMULATION OF REALISTIC IPYC CONDITIONS}

In this section, we describe Phase I simulation results which demonstrate the ability of the standard FBCVD model to discriminate different distributor configurations and different coating process conditions, both at overall operating conditions representative of the ORNL 2-inch coater at the beginning of the IPyC coating stage.

\subsection{DISTRIBUTOR DISCRIMINATION (MULTI-HOLE VS. SINGLE-HOLE INJECTOR)}

In this subsection, we describe coater simulations for realistic IPyC deposition conditions using two different injector types. Traditionally a single-hole injector was used for ORNL's 2-inch coater. However, ORNL staff members Rick Lowden and Jim Miller recently developed a multi-hole injector that they expected would produce a more optimal inlet gas distribution while maintaining the same total inlet gas flow. Specifically, they wanted to see if their inlet design would assist in maintaining a lower maximum gas velocity to minimize particle blow out from the top of the coater and also a higher minimum gas velocity to prevent unintentional particle discharge from the bottom.

The multi-hole design designed by Lowden and Miller uses the standard 50-mm $60^{\circ}$ cone and has a total of six $1.6 \mathrm{~mm}$ holes, with one hole located on the centerline and five equally spaced holes distributed circumferentially $47 \mathrm{~mm}$ from the center line. To test the ability of the coater model to handle a multihole distributor of this complexity, we carried out a full 3D simulation for IPyC conditions (with the 11 SLPM of inflow gas uniformly distributed among the six holes). For comparison, we also ran a similar simulation of the standard single-hole inlet coater. The simulations yielded huge amounts of data ( $\sim 75$ GB of data for a 10-second simulation), which included point information about gas and solids concentration fields, gas and solids velocity fields, and gas and solids temperatures at 80,000 locations (corresponding to grid cells) in the spatial domain typically recorded at $1000 \mathrm{~Hz}$. It should be noted that the level of spatial and temporal resolution for simulations such as these can be adjusted depending on the specific needs.

Even though the realistic simulation output file sizes are huge, previous experience has shown that it is typically better to retain all the primary output model variables so that any secondary variables or derived quantities can be computed via post processing as needed. However, we also find that case comparisons can be simpler and more quantitative if we consider a few key discriminating characteristics (DCs) that reflect relevant physics in the coating environment. We utilize such quantitative DCs in the following discussion along with graphical depictions of the gas and solids flows.

Figures 3 and 4 illustrate side view snapshots of void fraction contours from two pulsation cycles for the multi-hole and single-hole injectors respectively. The translucent solids contours are plotted for the entire bed so that that we can visualize the interiors of the bed. In addition, the solid surface contour corresponding to void fraction of 0.99 is shown and reflects the effective surface of the bed. The snapshots distinctly reveal that the different distributors produce dramatically different gas and solids mixing. In the multi-hole case, a broader, shorter and contorted gas pocket is formed from the rapidly expanding inlet gases and the motion of this bubble creates a less defined fountain zone with variability in spout shape, size and location. On the other hand, in the single-hole case, the bubbles are formed and aligned along the center of the axis with a taller well defined spout. 


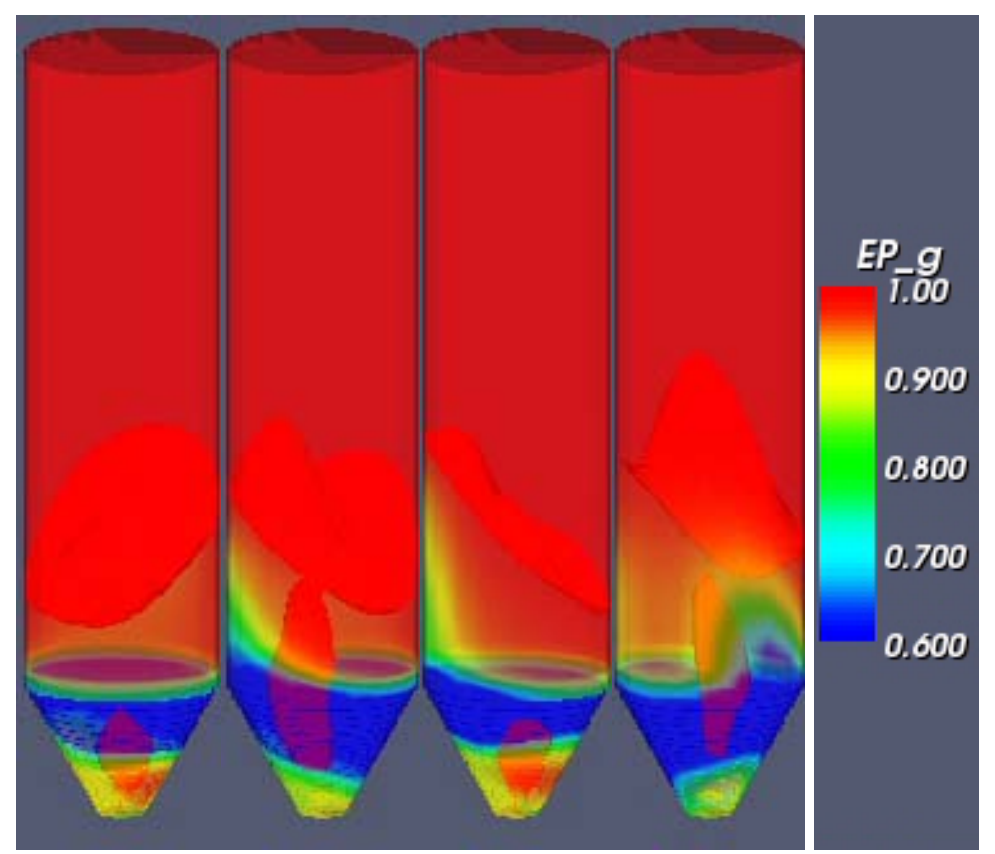

Fig. 3. Snapshots from two pulsation cycles of the side view of the spouted bed with multihole injector. Plotted are the translucent solid contours of the void fraction (similar to peering into a glass bed filled with transparent marbles colored with local void fraction) along with void fraction contour surface corresponding to void fraction of 0.99 . The void fraction surface represents a visual border between particles and gas. Here, the dynamic behavior of the spout along with the side-to-side sloshing of the bed is very evident. The color scheme for the void fraction is blue for solids and red for gas. The movie may be found at http://www.mfix.org/ORNL-TM-2006-520/Fig03.mpg . 


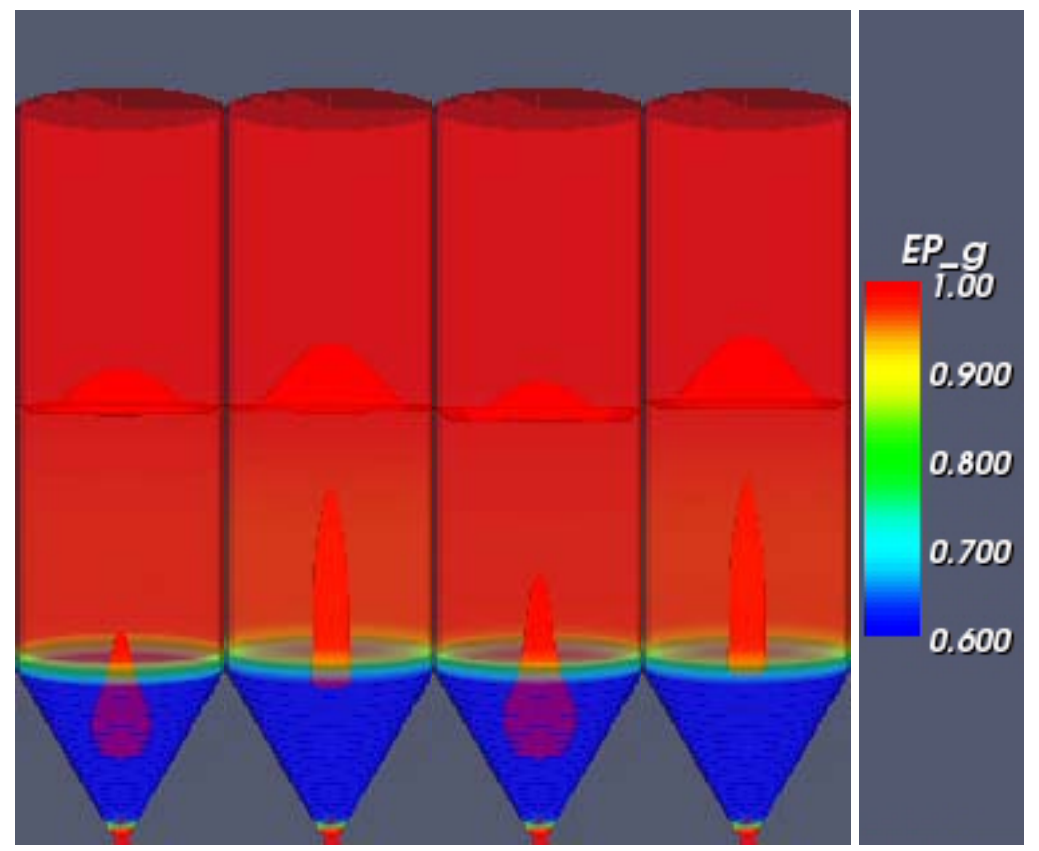

Fig. 4. Snapshots from two pulsation cycles of the side view of the spouted bed with the singlehole injector. Plotted are the translucent solid contours of the void fraction (similar to peering into a glass bed filled with transparent marbles colored with local void fraction) along with void fraction contour surface corresponding to void fraction of 0.99 . The void fraction surface represents a visual border between particles and gas. Here, unlike in Fig. 3, the spout is very stable to lateral motion with the fountain motion limited to the axial motion. The color scheme for the void fraction is blue for solids and red for gas. The movie may be found at http://www.mfix.org//ORNL-TM-2006-520/Fig04.mpg •

To better understand the effects of the dramatically different mixing patterns on heat transfer, the temperature surface contours (corresponding to $800 \mathrm{~K}$ ) and cross-sectional hydrogen mass fraction profiles are shown in figures 5 and 6 . The temperature contours denote the surface enveloping the cold gases as the inlet jet temperature is close to the ambient. In the multi-hole case, the jets are distinct and not uniform. Although the time average jet flows are equal, the changing level of solids above each multi-hole jet can cause different instantaneous back pressures and thus strong variations in the amount of jet/bubble formation over each jet. The net result is an excitation of lateral bed oscillation modes (the appearance is much like sloshing in containers of liquids). Because of its inherent symmetry, the singlehole inlet has much less tendency to excite lateral motions, and most of the inlet energy is directed axially in a highly coherent jet. Visually, the particle mixing in the multi-hole case appears to be much more rapid and chaotic. 

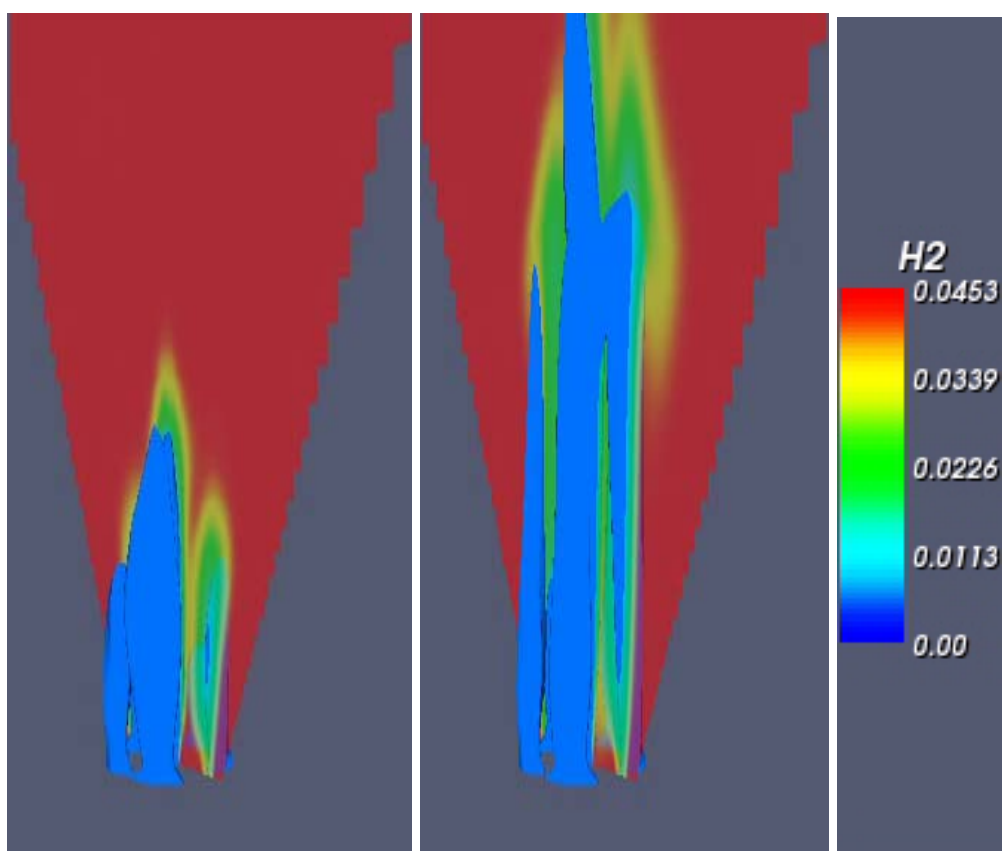

Fig. 5. Snapshots of the close-up of the multi-hole injector. Plotted are the centerline slice translucent solid contours of the $\mathrm{H}_{2}$ mass fraction along with temperature contour surface corresponding to temperature of $800 \mathrm{~K}$. The temperature surface represents a visual border between cold gas from the injectors to the hot gas in the coater. Here, the dynamic behavior of the inlet jets along with the hole-to-hole variation is evident. The color scheme for the $\mathbf{H}_{2}$ mass fraction is blue for zero concentration and red for highest concentration. The movie may be found at http://www.mfix.org/ORNL-TM-2006-520/Fig05.mpg . 

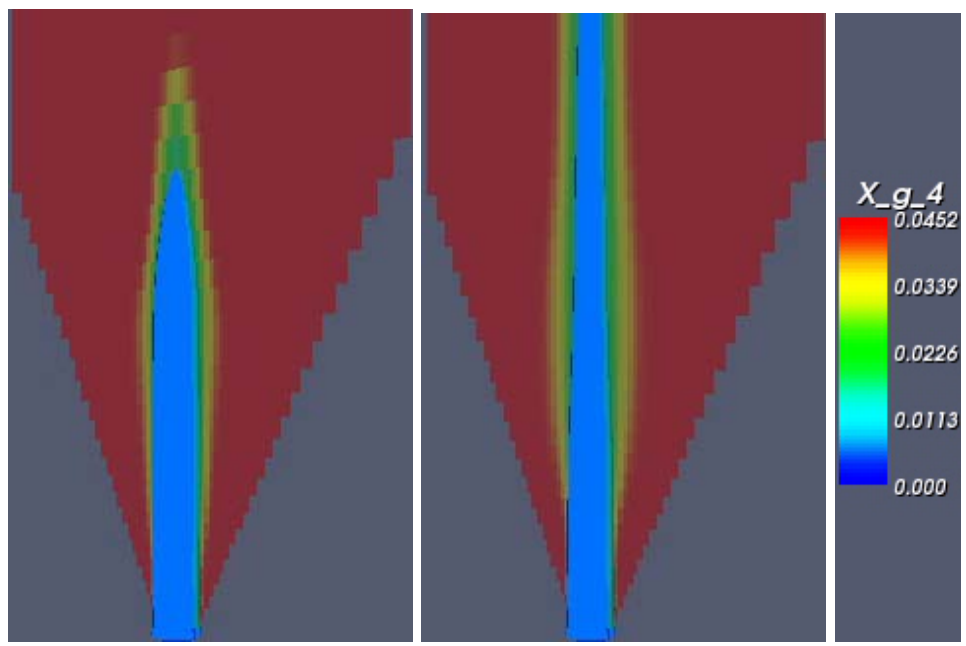

Fig. 6. Snapshots of the close-up of the single-hole injector. Plotted are the centerline slice translucent solid contours of the predicted $\mathrm{H}_{2}$ mass fraction along with temperature contour surface corresponding to temperature of $800 \mathrm{~K}$. The temperature surface represents a visual border between cold gas from the injectors to the hot gas in the coater. The color scheme for the $\mathrm{H}_{2}$ mass fraction is blue for zero concentration and red for highest concentration. The movie may be found at http://www.mfix.org/ORNL-TM-2006-520/Fig06.mpg .

In order to at least qualitatively compare the above predicted behavior of the multi-hole distributor with that actually observed for the multi-hole 2-inch coater, we constructed a simulated top view of the bed (with the 0.99 void fraction contour representing the surface) shown in Fig. 7. Corresponding still video images of the actual experimental multi-hole injector bed are shown in Fig. 8. Note that in the experimental case the gas is pure $\mathrm{Ar}$, the particles are hafnia $\left(\mathrm{HfO}_{2}\right)$, and the temperature is $900{ }^{\circ} \mathrm{C}$, somewhat lower than IPyC conditions. These changes were necessary because during IPyC conditions soot particles completely block optical access and the hot bed temperature 'washes out' video images. However, one can easily note the similar lateral motion of the spout from side-to-side in both cases. 


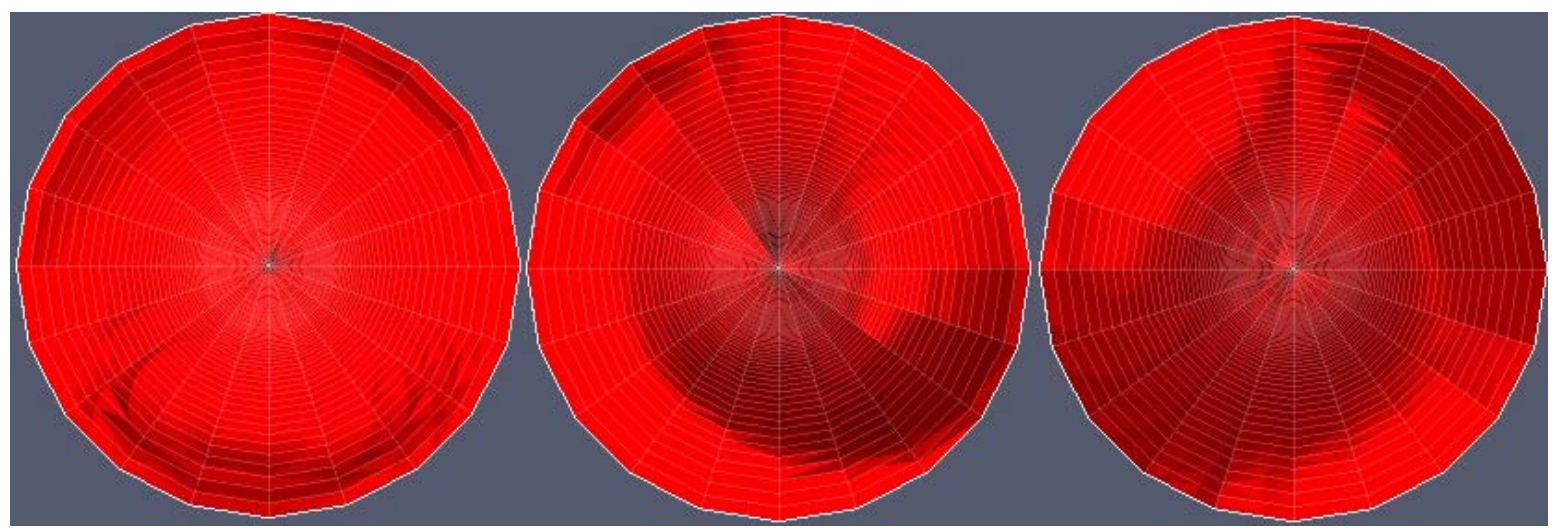

Fig. 7. Snapshots of the top view of the void fraction surface contour of 0.99 for multi-hole injector showing sloshing of the spout. This void fraction surface represents a visual border between particles and gas and is equivalent to a visual observation in the experiment from the top. The movie may be found at http://www.mfix.org/ORNL-TM-2006-520/Fig07.mpg .

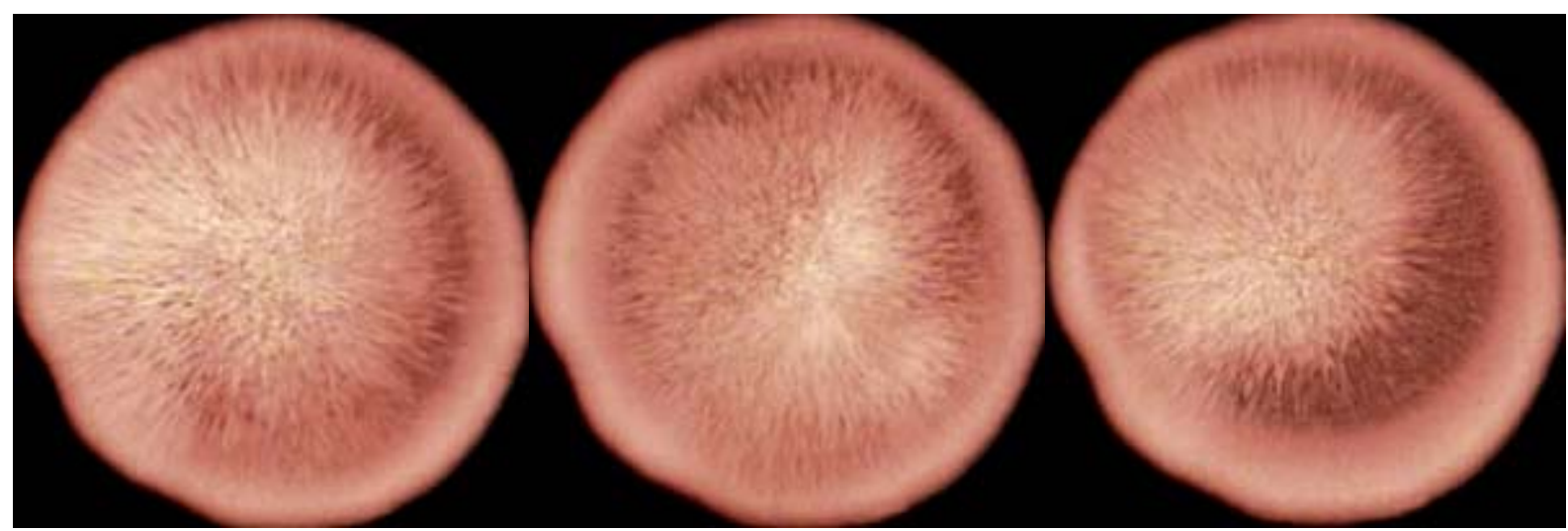

Fig. 8. Top view of multi-hole injector coater experiments. The conditions in this experiment are different from the simulations in Fig. 7 but this figure is shown here to illustrate the sloshing of the spout as observed in the simulations. The movie may be found at http://www.mfix.org/ORNL-TM-2006-520/Fig08.mpg .

The distributor simulations also predict that the different hydrodynamics produced by the multi-hole distributor should produce significantly different inlet pressure fluctuations. As shown in Fig. 9, which displays power spectral density functions (PSDs) for simulation cases, the peak fluctuation frequency is lower for the multi-hole case, reflecting the larger amount of global bed motion. 


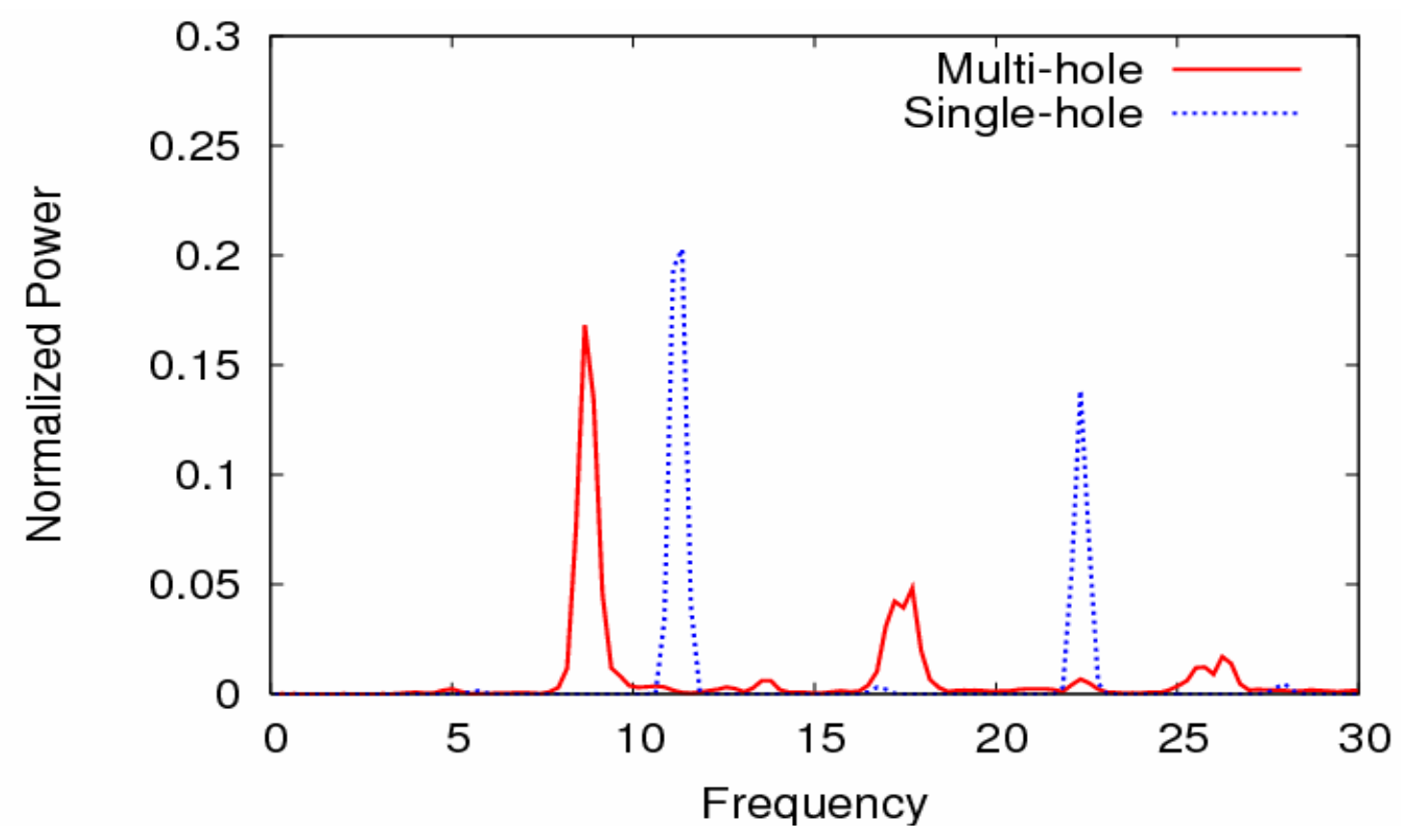

Fig. 9. Comparison of the pressure PSDs for the single- and multi-hole cases, from MFIX output. The PSDs clearly show the reduced frequency in the multi-hole case along with formation of complex sub-harmonics related to the sloshing motion of the bed.

Several quantitative DCs are summarized in Table 2 to illustrate the differences between the two distributors. The reader is referred to the Appendix A for a detailed explanation for each of these quantities. 
Table 2. Evaluated DCs for distributor discrimination cases

\begin{tabular}{|c|c|c|c|}
\hline $\begin{array}{l}\text { Discriminating } \\
\text { Characteristic }\end{array}$ & Multi-hole & Single-hole & Comments \\
\hline $\begin{array}{l}\text { Dimensionless Solids } \\
\text { Cycle Time }\end{array}$ & 20.75 & 35.34 & $40 \%$ reduction \\
\hline $\begin{array}{l}\text { Ballistic Particle } \\
\text { Profile }(10 \%)(\mathrm{cm})\end{array}$ & 8.56 & 10.97 & $\begin{array}{l}\text { Significant reduction in } \\
\text { fountain height }\end{array}$ \\
\hline $\mathrm{BPP}(1 \%)(\mathrm{cm})$ & 10.6 & 12.1 & \\
\hline $\operatorname{BPP}(0.1 \%)(\mathrm{cm})$ & 11.32 & 12.88 & \\
\hline $\begin{array}{l}\text { Net Solids-wall } \\
\text { Impact Rate }(\mathrm{g} / \mathrm{s})\end{array}$ & 32.77 & 17.83 & $\begin{array}{c}90 \% \text { increase in wall } \\
\text { impacts }\end{array}$ \\
\hline Core Diameter $(\mathrm{cm})$ & 2.96 & 2.18 & $\begin{array}{l}\text { Significant increase in } \\
\text { core diameter }\end{array}$ \\
\hline $\begin{array}{l}\text { Velocity, Gas @ } \\
\text { centerline static core } \\
\text { height }(\mathrm{CH})(\mathrm{cm} / \mathrm{s})\end{array}$ & 346 & 949 & $\begin{array}{l}\text { Significant decrease in } \\
\text { gas velocity }\end{array}$ \\
\hline $\begin{array}{l}\text { Velocity, Solids@ } \\
\mathrm{CH}(\mathrm{cm} / \mathrm{s})\end{array}$ & 39.8 & 80.4 & $50 \%$ reduction \\
\hline $\begin{array}{l}\text { Temperature, Gas @ } \\
\text { CH (K) }\end{array}$ & 1371 & 1000 & Gas heats up quickly \\
\hline $\begin{array}{l}\text { Temperature, Solids } \\
\text { @ } \mathrm{CH}(\mathrm{K})\end{array}$ & 1516 & 1486 & $\begin{array}{c}30 \mathrm{~K} \text { increase } \\
\text { (better mixing) }\end{array}$ \\
\hline $\begin{array}{l}\text { Granular fluctuation } \\
\text { Velocity @ } \mathrm{CH} \\
(\mathrm{cm} / \mathrm{s})\end{array}$ & 8.97 & 12.59 & \\
\hline $\begin{array}{l}\mathrm{H}_{2} \text { concentration @ } \\
\mathrm{CH}\end{array}$ & 0.0393 & 0.0243 & $\begin{array}{c}\text { Significant product } \\
\text { formation at bed height }\end{array}$ \\
\hline $\begin{array}{l}\mathrm{C}_{2} \mathrm{H}_{2} \text { concentration } \\
@ \text { @ } \mathrm{CH}\end{array}$ & 0.0221 & 0.0788 & $\begin{array}{l}\text { Significant decrease in } \\
\text { the reactant species }\end{array}$ \\
\hline $\begin{array}{l}\mathrm{C}_{3} \mathrm{H}_{6} \text { concentration } \\
\text { @ } \mathrm{CH}\end{array}$ & 0.0179 & 0.0639 & $\begin{array}{l}\text { Significant decrease in } \\
\text { the reactant species }\end{array}$ \\
\hline $\begin{array}{l}\text { Maximum inlet-gas } \\
\text { temperature gradient } \\
(\mathrm{GRADT})(\mathrm{K} / \mathrm{cm})\end{array}$ & 857.87 & 249.37 & $\begin{array}{l}\text { Huge difference in the } \\
\text { gas heat-up rate }\end{array}$ \\
\hline $\begin{array}{l}\text { Temperature @ } \\
\text { GRADT }(\mathrm{K})\end{array}$ & 434.5 & 461.9 & \\
\hline $\begin{array}{l}\text { Height of GRADT } \\
(\mathrm{cm})\end{array}$ & 0.25 & 1.382 & $\begin{array}{c}\text { Gas heats up very close to } \\
\text { the inlet }\end{array}$ \\
\hline
\end{tabular}

As seen in the visual snapshots and movies, the multi-hole and single-hole are very different hyrodynamically, and that difference is clearly reflected in most of the DCs. The quantitative differences are more pronounced in some while they are less different in others. The Dimensionless Solids Cycle Time (DCST) statistic confirms the visual observations that the dimensionless rate of solids turnover has drastically increased in the multi-hole case reflecting the increased mixing in the bed. Based on the physical picture we have presented and experimental observations, solids penetration into the freeboard (i.e., the fountain) are much lower in the multi-hole case as reflected in Ballistic Particle Profile (BPP). However, the side-to-side sloshing of the particles increases the wall impact significantly and is clearly 
captured by the Net Solids-wall Impact Rate (NSIR) statistic. In the lower portion of the bed, the core diameter increases for the multi-hole case reflecting the increased mixing zone. The corresponding spout gas velocity and particle velocity decrease indicating distributed energy from the multiple injectors. The core particle granular velocity (particle turbulence) decreases reflecting the reduced gradients in the flow.

Core gas temperature and peak gas temperature gradient are some of the largest DC variations observed, with a $50 \%$ and $300 \%$ difference, respectively. Core solids temperature also is higher reflecting increased solids mixing. We suspect that these temperatures and/or temperature gradients are major factors in homogenous carbon nucleation and thus might be especially important for discriminating these types of cases. The location of this peak gradient seems to be very close to the inlet as that is controlled by the solids circulation and the maximum gas temperature gradient occurs where the solids get entrained into the core. The temperature at which this maximum gradient occurs is at a lower point reflecting the proximity to the inlet. The reduced reactants in the core and increased product gas indicate the fast progress of the reactions due to higher temperatures and increased mixedness.

In conclusion, the multi-hole and single-hole simulations clearly show the effects of the different injector types on specific internal details within the coating bed. Unfortunately we do not yet have statistically validated measurements of the IPyC quality produced by the multi-hole design to correlate with the DCs. We will certainly be able to make such correlations when the quality measurements become available. We expect that interpretation of the ORNL multi-hole quality data in light of these large hydrodynamic differences should be very helpful in guiding future refinement of the DCs.

\subsection{OPERATING CONDITION DISCRIMINATION (TEMPERATURE VARIATION)}

In this subsection we describe the results of simulating three different IPyC coating temperatures, which correspond to parametric studies with the ORNL 2-inch surrogate coater. As before, we illustrate the predicted differences using both computer graphics and example DCs. Table 3 shows the list of three different cases simulated based on the ORNL IPyC study (Lowden et al., 2005), a baseline case (referred to as case 1) represents the standard coater condition producing the most desirable coating quality. Two extreme alternative operating conditions from Lowden's study kept the coating gas fraction constant (at 0.30 ) as temperature was varied between upper and lower limit, corresponding to cases 2 and 3 . These cases were chosen for Phase I because the IPyC quality has been well characterized, and the conditions we believed to still be close enough to reflect realistic operating variations in the pilot-scale reactor.

Table 3. Discriminating simulation cases

\begin{tabular}{|c|c|c|c|l|}
\hline Simulation case & Lowden's case & $\mathbf{T}\left[{ }^{\circ} \mathbf{C}\right]$ & IPyC density $\left[\mathbf{g} / \mathbf{c m}^{3}\right.$ ] & Comments \\
\hline 2 & 13 & 1170 & $1.978 \pm 0.007$ & Low temperature \\
\hline 1 & 12 & 1275 & $1.866 \pm 0.006$ & Baseline \\
\hline 3 & 2 & 1325 & $1.773 \pm 0.006$ & High temperature \\
\hline
\end{tabular}



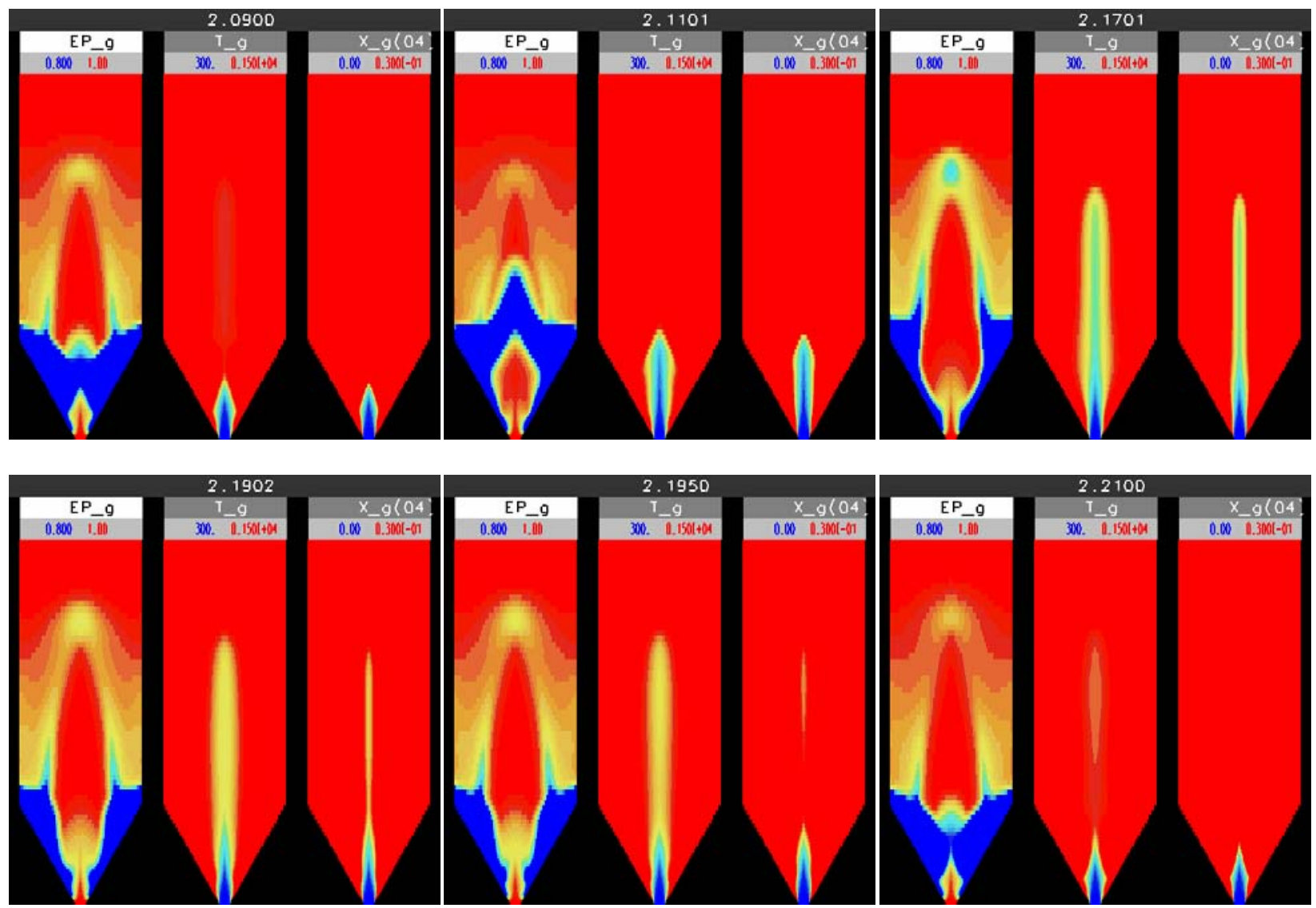

Fig. 10. Void fraction (first column, $\mathbf{E P}$ g), temperature (second column, $\mathbf{T} \_$g) and $\mathrm{H}_{2}$ species mass fraction (third column, $X \_g$ ) at six different time steps during the spouting process for baseline case 1 . Here, the relationship between the hydrodynamics pinching, temperature pulse and the species concentration is evident. The color scheme for the void fraction is blue for solids and red for gas; for temperature and species mass fraction, red for high and blue for low values (see numerical values at top). The movie may be found at http://www.mfix.org/ORNL-TM-2006520/Fig10.mpg .

Figure 10 illustrates the detailed spatio-temporal variations revealed by the simulation for Case 1 (the baseline IPyC case). Shown are solid contour snapshots of void fraction, temperature and the $\mathrm{H}_{2}$ species mass fractions at different times during the pulsing cycle. From the figure, we can infer that the pyrolysis of the $\mathrm{C}_{2} \mathrm{H}_{2}$ and $\mathrm{C}_{3} \mathrm{H}_{6}$ begins at the interface between the gas pocket and solid bed. We expect that the appearance of hydrogen is a good indicator of nascent solid-carbon ("snow") formation. Depending on the spout-formation stage, the carbon formation can be very close to the inlet, or this process can be deeper when the gas pocket has greater penetration into the bed. However, the conversion process happens well within the particle bed, and if all the carbon produced at the particle surface sticks to the particles, very high deposition efficiencies should be possible.

The snapshot sequence from the third to fifth frames indicates that the gas pocket (bubble) starts to heat inwards from the surrounding solids. At one point during this heat up, considerable hydrogen is formed within the $0.02 \mathrm{~s}$ interval between third and fourth snapshots. This implies that during the pulsation period of around $0.11-0.12 \mathrm{~s}$, significant carbon formation takes place in a very short segment of the overall cycle. We expect that the details of this rapid pyrolysis process could directly affect coating quality as it limits both the concentration and variability of the initial carbon "snow" available for deposition. The very short time (i.e., high rate) and small spatial extent (i.e., high gradient) of this 
pyrolysis process would make it very unlikely that it could ever be directly measured experimentally. Thus the availability of an accurate model for inferring variations in these details is clearly important.

Figures 11-13 show the simulated temperature contours for all three cases. The temperature range on solids contours and temperatures corresponding to the contour lines are kept constant so that one can contrast the figures easily. From the snapshots it is evident that as the temperature of the bed increases, the gas temperature in the coater increases, and the temperature gradients also increase. These in turn would be expected to alter the chemistry and subsequent coating quality.

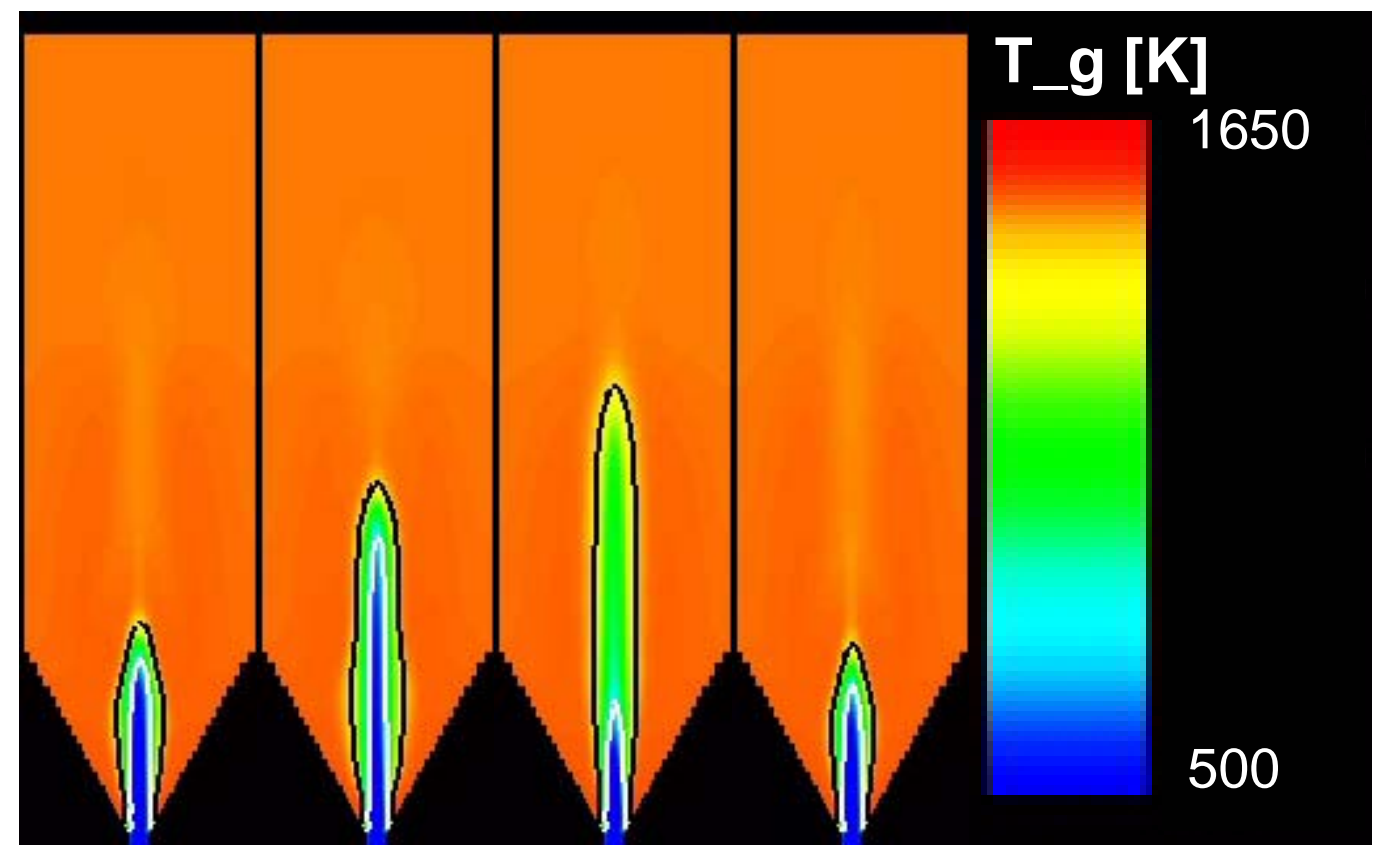

Fig. 11. Instantaneous temperature solid contours at four different instants during the spouting process for baseline case $1(1548 K)$. In addition, two contour lines corresponding to $800 \mathrm{~K}$ (white) and 1400K (black) are plotted to cold and high temperature gases. The movie may be found at http://www.mfix.org/ORNL-TM-2006-520/Fig11.mpg . 


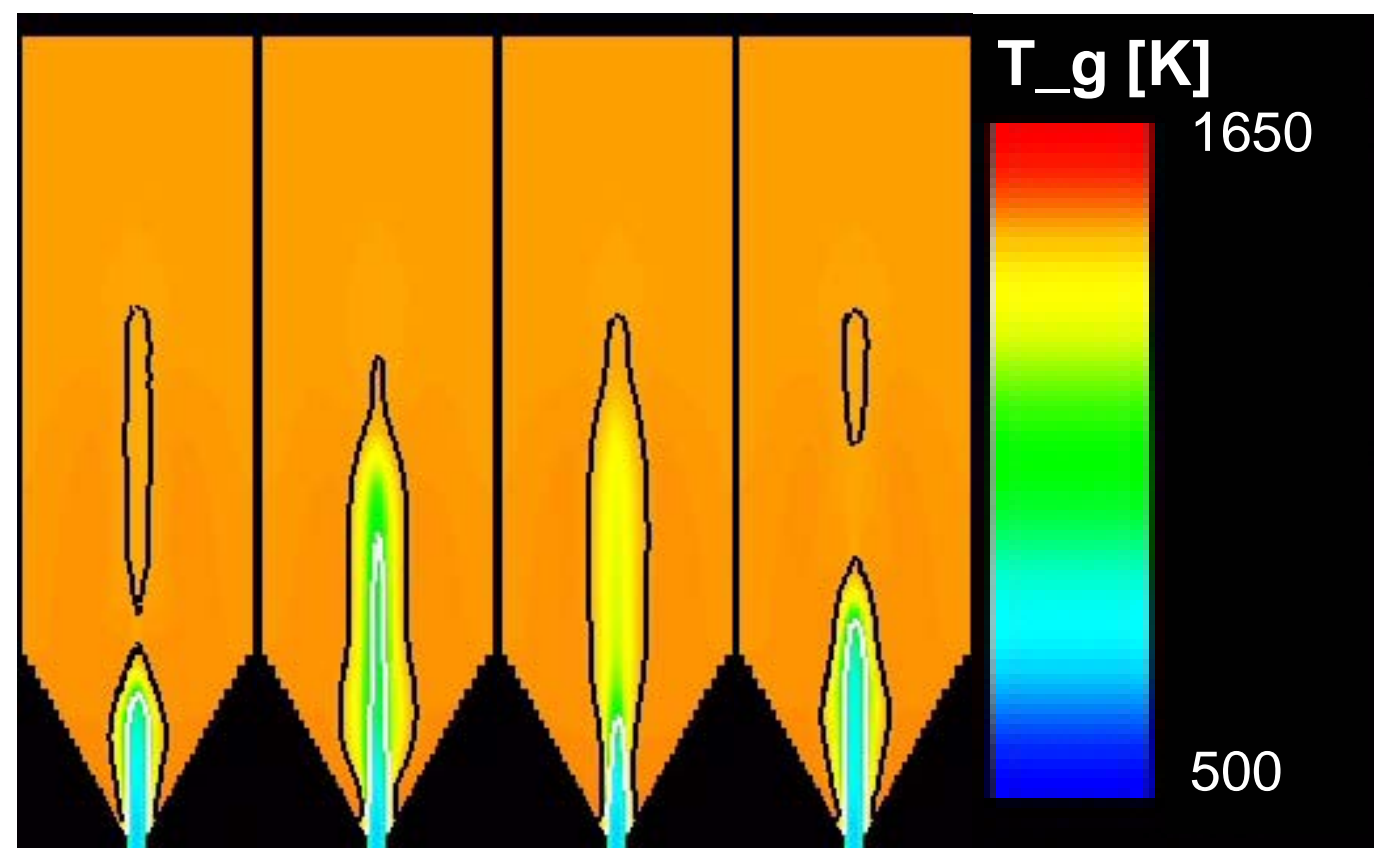

Fig. 12. Instantaneous temperature solid contours at four different instants during the spouting process for case 2 (1443K). Contour lines corresponding to $800 \mathrm{~K}$ (white) and $1400 \mathrm{~K}$ (black) are plotted to cold and high temperature gases. The movie may be found at http://www.mfix.org/ORNL-TM-2006-520/Fig12.mpg .

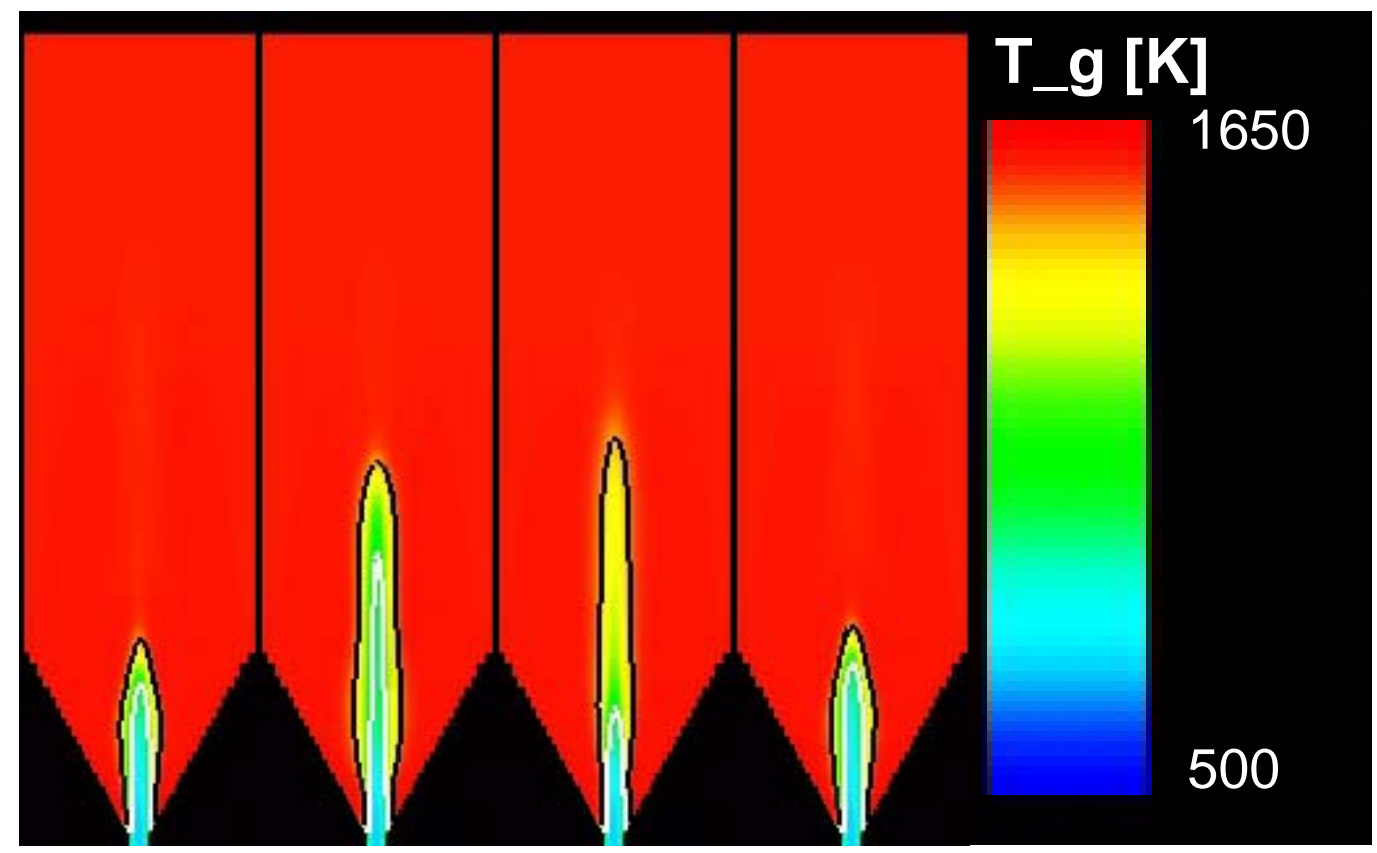

Fig. 13. Instantaneous temperature solid contours at four different instants during the spouting process for baseline case 3 (1598K). Contour lines corresponding to $800 \mathrm{~K}$ (white) and $1400 \mathrm{~K}$ (black) are plotted to cold and high temperature gases. The movie may be found at http://www.mfix.org/ORNL-TM-2006-520/Fig13.mpg .

To concisely summarize the effects described above, the computed values for selected DCs are listed in Table 4. The DCs are defined in detail in Appendix A. 
Table 4. Evaluated DCs for operating-conditions discrimination simulations

\begin{tabular}{|c|c|c|c|c|}
\hline $\begin{array}{l}\text { Discriminating } \\
\text { Characteristic }\end{array}$ & $\begin{array}{c}\text { Case } 2 \\
(1443 K)\end{array}$ & $\begin{array}{c}\text { Case 1 } \\
(1548 K)\end{array}$ & $\begin{array}{c}\text { Case } 3 \\
(1598 K)\end{array}$ & Comments \\
\hline $\begin{array}{l}\text { Dimensionless Solids } \\
\text { Cycle Time }\end{array}$ & 26.42 & 27.34 & 27.47 & \\
\hline $\begin{array}{l}\text { Ballistic Particle } \\
\text { Profile }(10 \%)(\mathrm{cm})\end{array}$ & 12.03 & 12.26 & 12.34 & \\
\hline $\operatorname{BPP}(1 \%)(\mathrm{cm})$ & 13.11 & 13.38 & 13.44 & \\
\hline $\operatorname{BPP}(0.1 \%)(\mathrm{cm})$ & 13.92 & 14.26 & 14.33 & \\
\hline $\begin{array}{l}\text { Net Solids-wall } \\
\text { Impact Rate }(\mathrm{g} / \mathrm{s})\end{array}$ & 17.27 & 20.29 & 21.23 & \\
\hline Core Diameter $(\mathrm{cm})$ & 2.29 & 2.326 & 2.338 & \\
\hline $\begin{array}{l}\text { Velocity, Gas @ } \\
\text { static core height } \\
(\mathrm{CH})(\mathrm{cm} / \mathrm{s})\end{array}$ & 1126 & 1168 & 1191 & $\sim 6 \%$ Difference \\
\hline $\begin{array}{l}\text { Velocity, Solids @ } \\
\text { CH (cm/s) }\end{array}$ & 83.1 & 86.6 & 87.6 & \\
\hline $\begin{array}{l}\text { Temperature, Gas@ } \\
\mathrm{CH}(\mathrm{K})\end{array}$ & 869 & 915 & 936 & $\sim 8 \%$ Difference \\
\hline $\begin{array}{l}\text { Temperature, Solids } \\
\text { @ } \mathrm{CH}(\mathrm{K})\end{array}$ & 1364 & 1459 & 1504 & $\sim 10 \%$ (Imposed) \\
\hline $\begin{array}{l}\text { Granular fluctuation } \\
\text { Velocity@ } @ \mathrm{CH} \\
(\mathrm{cm} / \mathrm{s})\end{array}$ & 11.98 & 12.53 & 12.67 & \\
\hline $\begin{array}{l}\mathrm{H}_{2} \text { concentration @ } \\
\mathrm{CH}\end{array}$ & 0.0207 & 0.0206 & 0.0205 & \\
\hline $\begin{array}{l}\mathrm{C}_{2} \mathrm{H}_{2} \text { concentration } \\
\text { (a) } \mathrm{CH}\end{array}$ & 0.0855 & 0.086 & 0.0865 & \\
\hline $\begin{array}{l}\mathrm{C}_{3} \mathrm{H}_{6} \text { concentration } \\
\text { @ } \mathrm{CH}\end{array}$ & 0.0729 & 0.0734 & 0.0737 & \\
\hline $\begin{array}{l}\text { Maximum inlet-gas } \\
\text { temperature gradient } \\
(\mathrm{GRADT})(\mathrm{K} / \mathrm{cm})\end{array}$ & 246.47 & 260.81 & 268.27 & $\begin{array}{c}\text { Biggest Difference } \\
(\sim 9 \%)\end{array}$ \\
\hline $\begin{array}{l}\text { Temperature @ } \\
\text { GRADT }(\mathrm{K})\end{array}$ & 552.6 & 560 & 565.29 & \\
\hline $\begin{array}{l}\text { Height of GRADT } \\
(\mathrm{cm})\end{array}$ & 1.869 & 1.869 & 1.869 & \\
\hline $\begin{array}{l}\text { Range, inlet-gas } \\
\text { pressure }(\mathrm{dPa})\end{array}$ & 60710 & 61895 & 62971 & \\
\hline $\begin{array}{l}\text { Standard deviation, } \\
\text { inlet-gas pressure } \\
(\mathrm{dPa})\end{array}$ & 13509 & 13526 & 13799 & $\begin{array}{l}\text { Big jump in variance } \\
\text { between cases } 1 \& 3 \\
\text { compared with } 1 \& 2\end{array}$ \\
\hline $\begin{array}{l}\text { Average Cycle } \\
\text { Frequency, inlet-gas } \\
\text { pressure }\left(\mathrm{s}^{-1}\right)\end{array}$ & 10.13 & 10.08 & 10.06 & \\
\hline
\end{tabular}

The DSCT statistic confirms that the dimensionless rate of solids turnover is increasing slightly with temperature, but the effect is small. As one might expect, solids penetration into the freeboard (i.e., the 
fountain) and particle-wall collisions are higher as temperature increases, as reflected in BPP and NSIR statistics. In the lower portion of the bed, the core diameter, spout gas velocity and particle velocity also increase with temperature. The core particle granular velocity (particle turbulence) clearly tracks with temperature as the sharper velocity gradients produce higher turbulence.

Core gas temperature and peak gas temperature gradient are some of the larger DC variations observed with a $9 \%$ change. As energy transfer from the furnace wall to solids is very effective, core solids temperature closely follows the furnace temperature. We suspect that these temperatures and/or temperature gradients are major factors in homogenous carbon nucleation and thus might be especially important for discriminating these types of cases. The location of the peak temperature gradients seems to be invariant in these geometrically similar cases as that will be controlled by the solids circulation and the maximum gas temperature gradient occurs where the solids get entrained into the core. Also, the variation in the absolute temperature at which this maximum gradient occurs is minimal.

Interestingly, the very limited set of currently predicted pyrolytic species profiles are almost invariant due to compensatory effects between reduced gas residence time and increased gas-particle mass-transfer rate. It is likely that more sophisticated chemical kinetics will be needed to correctly capture the impact of temperature on chemical species.

In conclusion, the simulations clearly show the effects of the different operating conditions on specific internal details within the coating bed. The $\sim 11 \%$ density variation of the IPyC layer seems to correlate well with the magnitude of the peak temperature gradient and core gas temperature in particular. Obviously, additional empirical studies and improved chemical kinetics will be needed to develop a model with more explicit predictive capabilities. Nevertheless, it is expected that the DCs for the current IPyC case 1 would be a good reference point for assessing future design and operating condition assessments. 


\section{CONCLUSIONS AND RECOMMENDATIONS}

The key overall conclusions based on the Phase I results are:

- The "standard" version of the ORNL FBCVD model is quite responsive to design and/or operating changes associated with the inlet gas flow design. As design of the gas distribution system is one of the dominant issues for scale-up, the model should be useful for discriminating among proposed scale-up options.

- Coating quality is known to be a strong function of local temperatures and reactant gas heating rate near the coater inlet, and these effects are clearly captured by the standard model.

- The list of discriminating characteristics originally proposed for the scale-up studies associated with AGR-2 should be expanded to include more detailed measures of spatial and temporal variations in temperature and reactive species. A modified DC list that can be fully generated using the standard model has been proposed (see Appendix A).

Besides staff time, the most critical limiting resource in utilizing the AGR FBCVD model for assisting AGR-2 scale-up will be parallel computer availability. These two factors will determine how many different design/operating options can be considered in the coming months.

Given the above Phase I results, the ORNL modeling team is confident that the standard model has sufficient fidelity and discrimination to warrant its use in a Phase II modeling assessment of potential scale-up designs and operating conditions. Model predictions should never be the sole basis for making future choices, but they should be very seriously considered in the selection process because they provide important information not available from any other source. If the program decides to proceed with Phase II modeling, the following parallel activities would serve to strengthen the ability of the scale-up team to maximally utilize the information in standard model predictions:

- Measurements of the coefficient of restitution and internal angle of friction for surrogate and/or NUCO particles at different stages of coating and elevated temperatures.

- Additional thermocouple and heat-transfer measurements in the inlet sections of the surrogate coaters at different stages of coating.

- CARPT measurements of global solids circulation rates over as wide a range of operating conditions and distributor designs as possible.

- Continued refinement of the appropriate set of discriminating characteristics to be used for comparing different options.

- Development and limited validation of automated computer routines for processing AGR FBCVD coater model output to produce summaries of the most current list of defined DCs (updated lists would be made by post-processing existing output files and would not require additional simulation runs). 



\section{REFERENCES}

Boyalakuntla D., S. Pannala, C. E. A. Finney, and C. S. Daw, ORNL FY05 Process Modeling Summary Report for the Advanced Gas Reactor Fuel Development and Qualification Program: Hydrodynamics, Heat and Mass Transfer, Oak Ridge National Laboratory Technical Report ORNL/CF-05/13, August 2005.

Boyalakuntla D. S., C. E. A. Finney, C. S. Daw and S. Pannala, Simulating the Hydrodynamics of Spouted Beds Using a Continuum Formulation, AIChE Annual Meeting, 2005.

Finney C. E. A., S. Pannala, D. Boyalakuntla, and C. S. Daw, ORNL FY05 Process Modeling Summary Report for the Advanced Gas Reactor Fuel Development and Qualification Program: Hydrodynamics, Heat, and Mass Transfer for NUCO Particles, Oak Ridge National Laboratory Technical Report ORNL/CF-05/14, September 2005.

Gunn D. J., "Transfer of heat or mass to particles in fixed and fluidized beds", International Journal of Heat and Mass Transfer 21: 467-476, 1978.

Heit W., SiC in Nuclear Technology, Handbook of Inorganic Chemistry, Silicon Suppl. Vol. B3, 478-500, 1986.

Lowden R. A., J. D. Hunn, S. D. Nunn, A. K. Kercher, J. R. Price, P. A. Menschhofer and G. E. Jellison, Jr. Effects of Deposition Conditions on the Properties of Pyrolytic Carbon Deposited in a Fluidized Bed, ORNL/TM-2005/533, September 2005.

Miller J. H., personal communication, February 2004.

Pannala S., C. S. Daw, C. E. A. Finney, D. Boyalakuntla, D. Bruns and J. Zhou, ORNL FY04 Process Modeling Summary Report for the Advanced Gas Reactor Fuel Development and Qualification Program, Oak Ridge National Laboratory Technical Report ORNL/CF-04/11, September 2004.

Pannala S., D. Boyalakuntla, C. E. A. Finney, J. H. Miller, R. A. Lowden and C. S. Daw, Simulations of Spouted Beds for Coating TRISO Fuel Particles, AIChE Annual Meeting, 2005.

Zhou J., D. D. Bruns, C. E. A. Finney, C. S. Daw and S. Pannala, Hydrodynamic Correlations with Experimental Results from Cold Mockup Spouted Beds for Advanced Fuel Particle Coating, AIChE Annual Meeting, 2005. 

APPENDiX A

Proposed Discriminating ChARACTERISTICS 



\section{APPENDIX A. PROPOSED DISCRIMINATING CHARACTERISTICS}

Based on recent experience with the multi-hole injector and IPyC temperature variation simulations, we propose the following list of DCs. This list is not comprehensive and subject to further refinement based on the feedback from Doug Marshall and Charles Barnes of Idaho National Laboratory. In addition, field testing of these DCs on different cases needs to be performed to ascertain the importance of these DCs and retain the ones which are important or add additional ones as needed. In the longer run, appropriate weights must be developed for each of the DCs so that a weighted least-squares evaluation can be performed against a reference case to determine whether a coater design is good or bad. It is essential to mention here that these DCs do not in themselves have information about particle quality but are related to the processes dictating the particle quality. Thus, a reference case where good quality product has been manufactured should always exist to be able to ascertain the applicability of a new design.

Table 5 lists the proposed DCs, their units and a brief description.

Table 5. Definitions of proposed discriminating characteristics

\begin{tabular}{|c|c|c|c|}
\hline Name & Label & Units & Description \\
\hline $\begin{array}{l}\text { Dimensionless } \\
\text { solids cycle time }\end{array}$ & DSCT & - & $\begin{array}{l}\text { Time-averaged global measure, without regard to the number of } \\
\text { spouts, of solids passages through the static bed height using } \\
\text { particle-tracking methods. }\end{array}$ \\
\hline $\begin{array}{l}\text { Solids mass } \\
\text { circulation rate }\end{array}$ & SMCR & $1 / \mathrm{s}$ & $\begin{array}{l}\text { Time-averaged ratio of the net solids flux through the static bed } \\
\text { height plane to the total bed solids mass, indicating bed } \\
\text { turnovers/unit time, determined using particle-tracking methods. } \\
\text { This rate could also be non-dimensionalized as above if desired. } \\
\text { This will be different from DSCT only when there are stagnation } \\
\text { zones or multiple recirculation zones. }\end{array}$ \\
\hline $\begin{array}{l}\text { Ballistic particle } \\
\text { profile }\end{array}$ & BPP & $\mathrm{cm}$ & $\begin{array}{l}\text { Defined and reported at three elevations where the net upward } \\
\text { particle flux rate has dropped to } 10 \%, 1 \% \text {, and } 0.1 \% \text { of the } \\
\text { upward flux rate at the static bed height; elevations are kept in } \\
\text { dimensional form to compare with actual coater dimensions that } \\
\text { can vary by site. }\end{array}$ \\
\hline $\begin{array}{l}\text { Net solids-wall } \\
\text { impact rate }\end{array}$ & NSIR & $\mathrm{g} / \mathrm{s}$ & $\begin{array}{l}\text { Global measure of the mass of solids/unit time hitting the coater } \\
\text { walls above the static bed height, indicating fountain width } \\
\text { related to coater diameter and how much ballistic particle-wall } \\
\text { interaction there is. This could also be non-dimensionalized by } \\
\text { the solids mass circulation rate. }\end{array}$ \\
\hline $\begin{array}{l}\text { Time-averaged } \\
\text { core diameter }\end{array}$ & $\mathrm{CD}$ & $\mathrm{cm}$ & $\begin{array}{l}\text { Based on time-averaged solids flux profiles at the static bed } \\
\text { height, corresponding to the circular area defined by the } \\
\text { transition from a time-average upward solids flux to a time- } \\
\text { average downward solids flux; values should be reported for each } \\
\text { spout. }\end{array}$ \\
\hline $\begin{array}{l}\text { Gas velocity at } \\
\text { static core height }\end{array}$ & $\mathrm{VGCH}$ & $\mathrm{cm} / \mathrm{s}$ & $\begin{array}{l}\text { Time-averaged gas velocity on the core centerline at the } \\
\text { centerline core static bed height }(\mathrm{CH}) \text {; values should be reported } \\
\text { for each spout. }\end{array}$ \\
\hline $\begin{array}{l}\text { Solids velocity at } \\
\mathrm{CH}\end{array}$ & VSCH & $\mathrm{cm} / \mathrm{s}$ & $\begin{array}{l}\text { Time-averaged solids velocity at } \mathrm{CH} \text {; values should be reported } \\
\text { for each spout. }\end{array}$ \\
\hline $\begin{array}{l}\text { Gas temperature } \\
\text { at } \mathrm{CH}\end{array}$ & TGCH & $\mathrm{K}$ & $\begin{array}{l}\text { Time-averaged gas temperature at } \mathrm{CH} \text {; values should be reported } \\
\text { for each spout. }\end{array}$ \\
\hline $\begin{array}{l}\text { Solids } \\
\text { temperature at } \mathrm{CH}\end{array}$ & $\mathrm{TSCH}$ & K & $\begin{array}{l}\text { Time-averaged solids temperature at } \mathrm{CH} \text {; values should be } \\
\text { reported for each spout. }\end{array}$ \\
\hline $\begin{array}{l}\text { Concentration of } \\
\text { species } X \text { at } \mathrm{CH}\end{array}$ & $X \mathrm{CH}$ & - & $\begin{array}{l}\text { Time-averaged concentration of species } X \text { at } \mathrm{CH} \text {; values should } \\
\text { be reported for each spout. }\end{array}$ \\
\hline
\end{tabular}




\begin{tabular}{|c|c|c|c|}
\hline $\begin{array}{l}\text { Granular } \\
\text { fluctuation } \\
\text { velocity at } \mathrm{CH}\end{array}$ & $\mathrm{GVCH}$ & $\mathrm{cm} / \mathrm{s}$ & $\begin{array}{l}\text { Time-averaged granular fluctuation velocity for particles at } \mathrm{CH} \text {, } \\
\text { indicating the intensity of particle-particle collisions in the core } \\
\text { zone; values should be reported for each spout. }\end{array}$ \\
\hline $\begin{array}{l}\text { Annular-zone gas } \\
\text { fraction }\end{array}$ & AGF & - & $\begin{array}{l}\text { Time-averaged fraction of inlet gas flowing external to the spout } \\
\text { core (i.e., percolating through the annular zone), measured at the } \\
\text { static bed height. }\end{array}$ \\
\hline $\begin{array}{l}\text { Extent of bed } \\
\text { stagnation }\end{array}$ & STAGF & $\%$ & $\begin{array}{l}\text { Global fraction of the bed below the static bed height where the } \\
\text { time-averaged absolute solids velocity is less than a defined } \\
\text { critical value }(e . g ., 0.3 \mathrm{~cm} / \mathrm{s}) \text {. }\end{array}$ \\
\hline $\begin{array}{l}\text { Maximum inlet- } \\
\text { gas temperature } \\
\text { gradient }\end{array}$ & GRADT & $\mathrm{K} / \mathrm{cm}$ & $\begin{array}{l}\text { Determined for the centerline of each reactant gas jet } \\
\text { immediately at the base of the coater where the gas first contacts } \\
\text { the dense particle bed (as opposed to the location where the gas } \\
\text { line enters the furnace or sub-bed hot zone). }\end{array}$ \\
\hline $\begin{array}{l}\text { Temperature at } \\
\text { GRADT }\end{array}$ & TGRADT & $\mathrm{K}$ & $\begin{array}{l}\text { Temperature value at the maximum inlet-gas temperature } \\
\text { gradient }\end{array}$ \\
\hline $\begin{array}{l}\text { Location at } \\
\text { GRADT }\end{array}$ & YGRADT & $\mathrm{cm}$ & Location (height) at the maximum inlet-gas temperature gradient \\
\hline $\begin{array}{l}\text { Inlet-gas pressure } \\
\text { range }\end{array}$ & PRANGE & $\mathrm{dPa}$ & $\begin{array}{l}\text { Defined as the maximum minus minimum of the inlet-gas } \\
\text { pressure time series; the location and sampling method of the } \\
\text { inlet is defined in a standard manner. }\end{array}$ \\
\hline $\begin{array}{l}\text { Inlet-gas pressure } \\
\text { standard deviation }\end{array}$ & PSIGMA & $\mathrm{dPa}$ & $\begin{array}{l}\text { Defined as the standard deviation of the inlet-gas pressure time } \\
\text { series. }\end{array}$ \\
\hline $\begin{array}{l}\text { Inlet-gas pressure } \\
\text { average cycle } \\
\text { frequency }\end{array}$ & $\mathrm{PACF}$ & $1 / \mathrm{s}$ & $\begin{array}{l}\text { Defined as the average cycle frequency of the inlet-gas pressure } \\
\text { time series; the ACF typically is defined as the inverse of the } \\
\text { expected time between successive upward crossings of the time- } \\
\text { series mean. }\end{array}$ \\
\hline
\end{tabular}

The following assumptions and interpretations of the physical processes led to the above set of proposed DCs.

- The basic type of reactor required for coating is some type of spouted bed, which might consist of a single or multiple collection of parallel spouts.

- Most of the coating process occurs in the central core of each spout, where the particles are fully entrained by the gas. In simplest terms, this zone can be described as a plug flow reactor with "leaky" walls.

- Within the core, key parameters affecting coating quality should be:

o Gas heating rate

o Gas-particle temperature difference

o Gas-particle slip velocity

o Gas residence time

o Steadiness/unsteadiness of gas flow

o Particle-particle collision intensity and frequency

o Radial "leak" rate for gas and particles from the core

o Homogeneous and heterogeneous reaction time scales (exponentially dependent on temperature)

- Once particles enter the fountain (freeboard), interactions between the gas and solids are minimal. Key quality-related parameters here are:

o Particle-particle collision intensity and frequency

o Particle-wall collision intensity and frequency

o Presence of wall deposits

o Particles that have returned to the bed flow in the annular region as a dense "granular" 
phase much like solids in a hopper. In simplest terms, this is like a hopper feeding the bottom of the plug flow reactor.

- Within the annular zone, key parameters affecting coating quality should be:

o Uniformity of particle flow (e.g., mass flow versus funnel flow and formation of stagnant zones)

o Arching tendency near the bottom (i.e., flow into the particle entrainment zone)

o Radial "leak" rate for gas and particles from the core

o Wall sticking/friction

o Presence of wall deposits

0 Oscillations in the bed height (e.g., slugging-like behavior)

- The interface between the annular zone and plug flow reactor is the entrainment zone.

- Key parameters affecting quality in the entrainment zone are:

o Gas inlet velocity (direction and magnitude)

o Steadiness of particle and gas flows

o Gas temperature and heating rate

o Presence of wall deposits 